\title{
Synthesis and performance in OLEDs of selenium-containing phosphorescent emitters with red emission colour deeper than corresponding NTSC standard.
}

\author{
Pavel Arsenyan, ${ }^{* a}$ Alla Petrenko, ${ }^{\mathrm{a}}$ Karolis Leitonas ${ }^{\mathrm{b}}$, Dmytro Volyniuk ${ }^{\mathrm{b}}$, Jurate Simokaitiene ${ }^{\mathrm{b}}$, Tomas \\ Klinavičius ${ }^{\mathrm{c}}$, Eigirdas Skuodis ${ }^{\mathrm{b}}$, Jiun-Haw Lee ${ }^{\mathrm{d}}$,Juozas Vidas Gražulevičius ${ }^{* b}$ \\ ${ }^{a}$ Latvian Institute of Organic Synthesis, Aizkraukles 21, LV-1006, Riga, Latvia; \\ b Kaunas University of Technology, Department of Polymer Chemistry and Technology, Radvilenu pl. 19, LT-50254, \\ Kaunas, Lithuania; \\ ${ }^{c}$ Institute of Materials Science, Kaunas University of Technology, K. Baršausko St. 59, LT51423 Kaunas, Lithuania \\ ${ }^{\mathrm{d}}$ Graduate Institute of Photonics and Optoelectronics, National Taiwan University, No. 1, Sec. 4, Roosevelt Rd., Taipei, \\ Taiwan
}

\section{Supporting Information}

\section{Instrumentation}

Thermal properties. Differential scanning calorimetry (DSC) measurements were performed with DSC Q2000 calorimeter (TA Instruments) at heating and cooling rates of $10 \mathrm{oC} / \mathrm{min}$ in a nitrogen atmosphere. Thermogravimetric analysis (TGA) was carried out on a TA Instruments Q50 apparatus in a nitrogen atmosphere at a heating rate of $20^{\circ} \mathrm{C} / \mathrm{min}$.

The cyclic voltammetry (CV) measurements were performed using the $\mu$ AutolabIII electrochemical impedance analyser with a three-electrode system where $\mathrm{Ag} / \mathrm{Ag}^{+}$as reference electrode and a Pt wire counter electrode and Pt disc working electrode. Solutions of the compounds were measured in dry dichlormethane also $0.1 \mathrm{M}$ tetrabutylammonium hexafluorophosphate was used as supporting electrolyte. The measurements were performed under argon atmosphere at $100 \mathrm{mV} / \mathrm{s}$ potential rate at room temperature. At the end of the process, ferrocene was added as internal reference. Ionization potential $\left(I_{p}{ }^{C V}\right)$ was estimated from the onset oxidation potential using the relationship $I_{p}{ }^{C V}=4.8+$ Eox.vsFC.

Emission spectra and PL decays of the compounds were recorded using an Edinburgh Instruments FLS980 spectrometer and the PicoQuant LDH-D-C-375 laser (wavelength $374 \mathrm{~nm}$ ) as the excitation source. UV/Vis absorbance spectra of solutions and solid samples were measured using the Avantes AvaSpec-2048XL spectrometer. Variable temperature liquid nitrogen cryostat Optistat DN2 was used for the characterization of photophysical properties of samples at 77 - $300 \mathrm{~K}$ temperatures in inert atmosphere $\left(\mathrm{N}_{2}\right)$. Photoluminescence quantum yields were measured using integrated sphere (inner diameter of $120 \mathrm{~mm}$ ) calibrated with two standards: quinine sulphate in 0.1 
$\mathrm{M} \mathrm{H}_{2} \mathrm{SO}_{4}$ and rhodamine $6 \mathrm{G}$ in ethanol. Degassed solutions were prepared by pumping air out at frozen solutions.

Ionization potentials (IP) of the layers of the compounds were measured by the photoelectron emission method in air $\left.{ }^{1}\right]$. Samples on glass substrates with conductive layer of indium tin oxide (ITO) were prepared by drop casting using tetrahydrofuran (THF) solutions of investigated compounds. The deuterium light source (ASBN-D130-CM), monochromator (CM110 1/8m) the Keithley $6517 \mathrm{~B}$ were used in the measurements as it described before $\left[^{2}\right]$.

Deep-red phosphorescence OLEDs were fabricated by vacuum deposition. Light-emitting layers of white hybrid OLEDs were fabricated by solution processes. The layers were spin-coated onto pre-cleaned glass subtracts with ITO patterning. It was possible to fabricate seven independent square shaped devices with area $6 \mathrm{~mm}^{2}$ on one substrate. The glass substrates were cleaned using pure acetone. In the spin-coating procedure, toluene solutions containing different ratio of three emitters with the concentration of $3 \mathrm{mg} / \mathrm{ml}$ were used. Light-emitting layers were spin-coated at $2000 \mathrm{rpm}$ with rotation acceleration of $50 \mathrm{rpm} / \mathrm{sec}$ during 100 seconds. After spin-coating, the layers were dried at $70{ }^{\circ} \mathrm{C}$ during $30 \mathrm{~min}$ in inert atmosphere. Other functional layers such as TSPO1, TPBi, LiF and aluminium layers were deposited under the vacuum higher than $2 \times 10^{-6}$ mBar using vacuum equipment from Kurt J. Lesker in-built in an MB EcoVap4G glove box. Density-voltage and luminance-voltage characteristics were recorded utilizing certificated photodiode PH100-Si-HA-D0 together with the PC-Based Power and Energy Monitor 11S-LINK (from STANDA) and Keithley 2400C source meter. Electroluminescence (EL) spectra were taken by the Avantes AvaSpec-2048XL spectrometer. Device efficiencies were calculated using the luminance, current density, and EL spectra. The chromaticity coordinates ( $\mathrm{x}, \mathrm{y})$ of the devices were estimated using electroluminescence spectra.

\section{Figures}

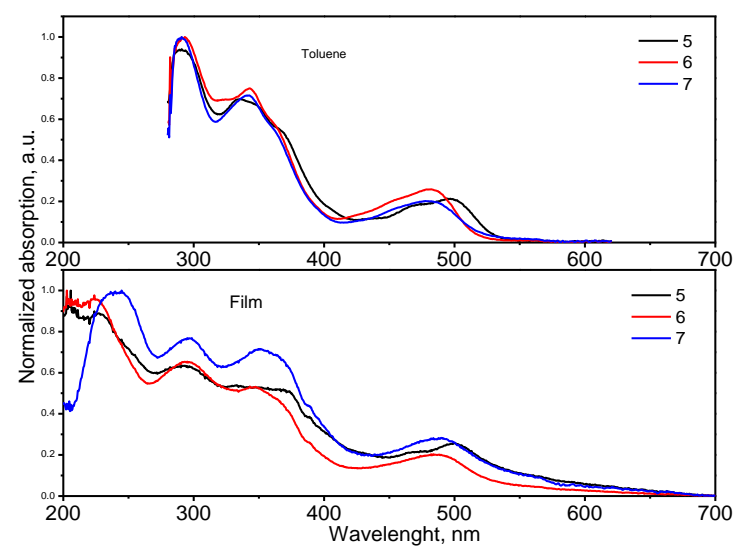

a)
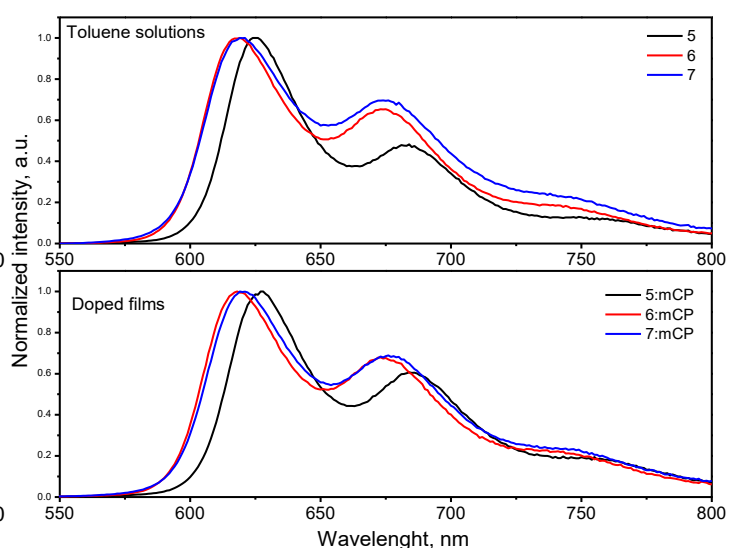

b) 


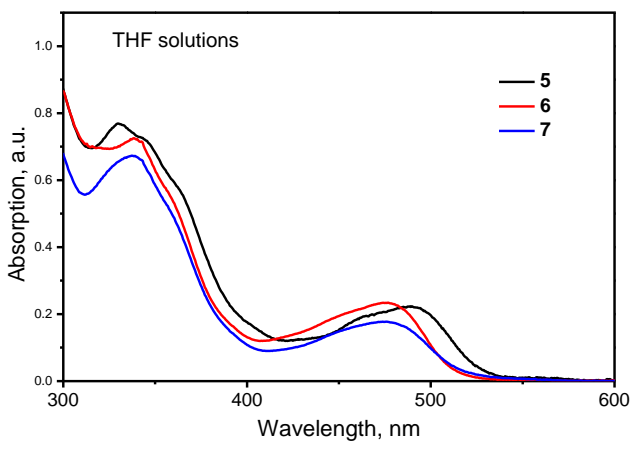

c)

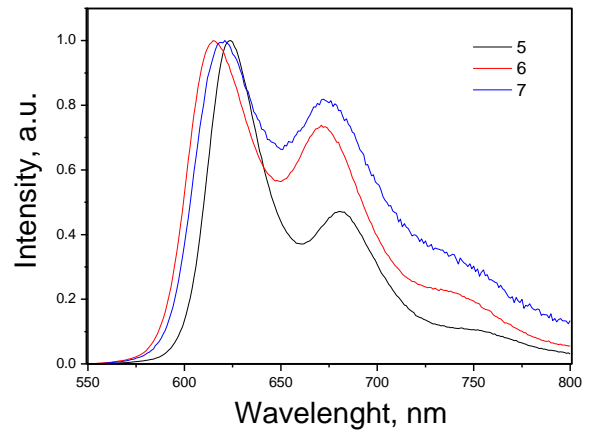

d)

Figure S1. Absorption spectra of the dilute toluene solutions $\left(10^{-5} \mathrm{M}\right)$ and non-doped films (a) and PL spectra of the dilute toluene and doped films using the mCP host (b) for compounds 5-7. Absorption (c) and PL (d) spectra for compounds 5-7 in the dilute THF solutions $\left(10^{-5} \mathrm{M}\right)$. The excitation wavelength $\lambda_{\text {ex. }}=350 \mathrm{~nm}$ was used for the PL spectra measurements.

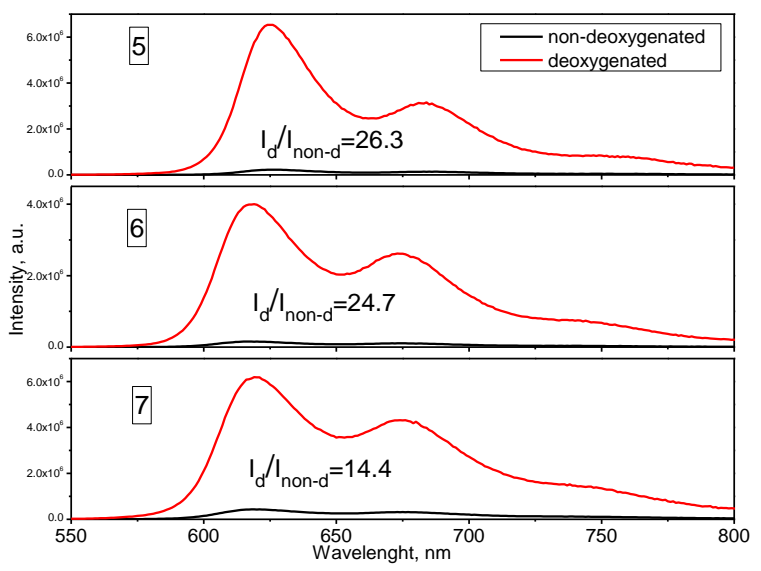

a)

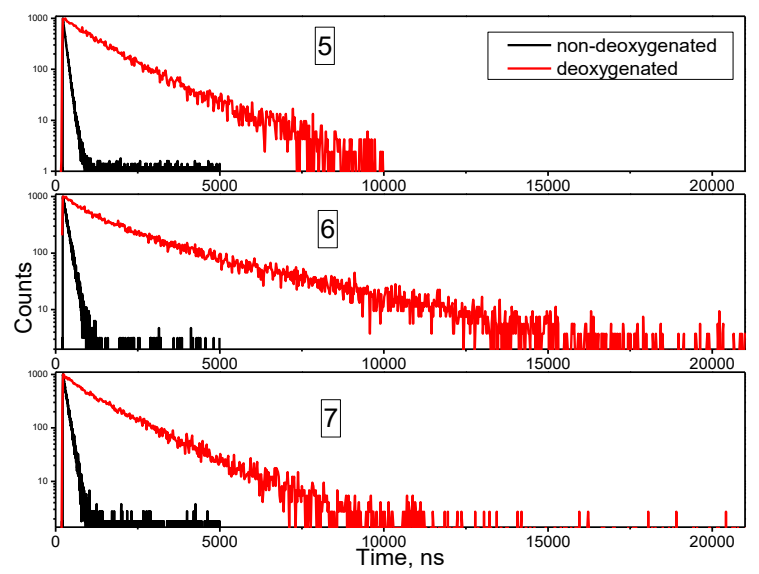

c)

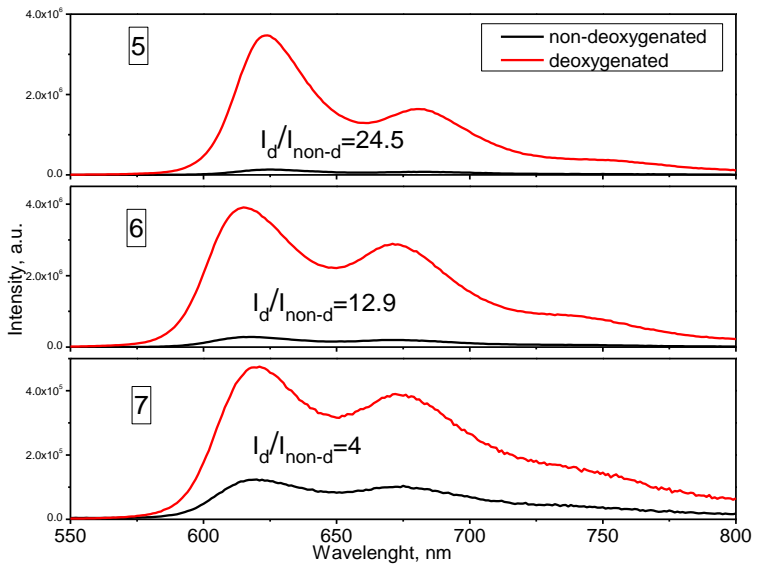

b)

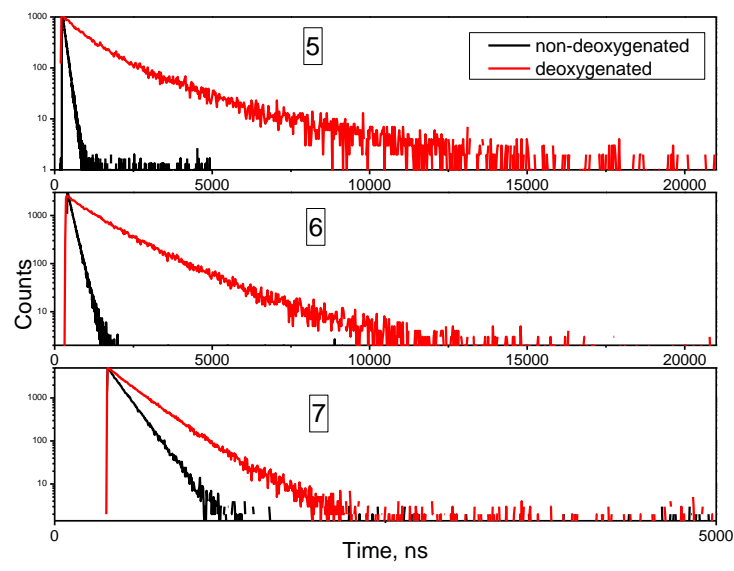

d)

Figure S2. PL spectra (a, b) and PL decays (c, d) of non-deoxygenated and deoxygenated dilute toluene (a, c) and THF (b, d) solutions $\left(10^{-5} \mathrm{M}\right)$ for compounds 5-7. The excitation wavelengths $\lambda_{\text {ex. }}=350 \mathrm{~nm}$ and $\lambda_{\text {ex. }}=374 \mathrm{~nm}$ were used for the PL spectra and PL decays measurements, respectively. 


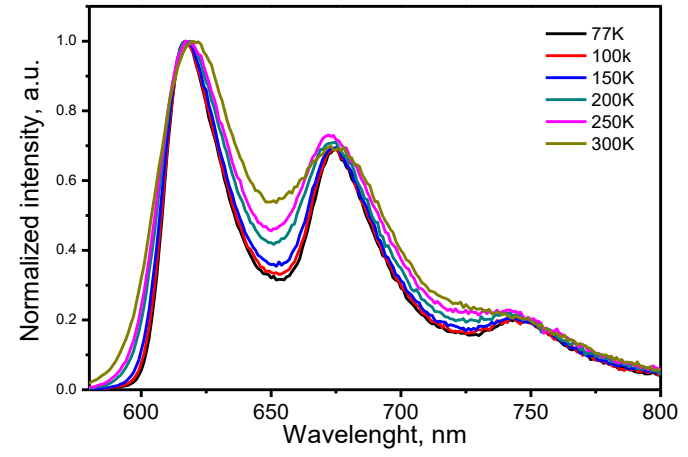

a)

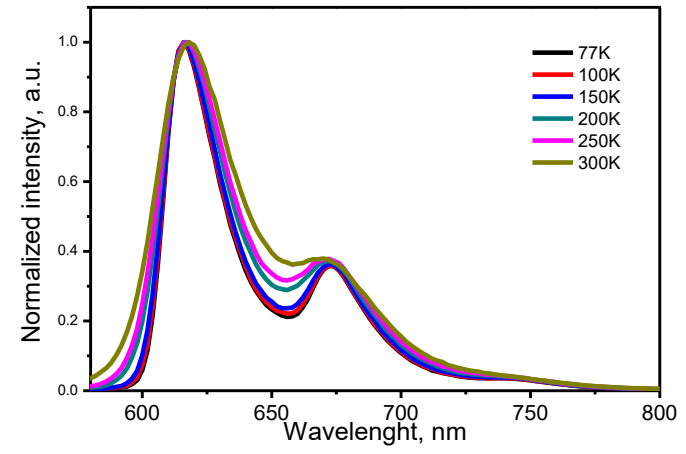

b)

Figure S3. PL spectra of compound 6 (a) and 7 (b) in $5 \mathrm{wt} \%$ doped films using the mCP host at different temperatures. The excitation wavelength $\lambda_{\text {ex. }}=350 \mathrm{~nm}$ was used for the PL spectra measurements.

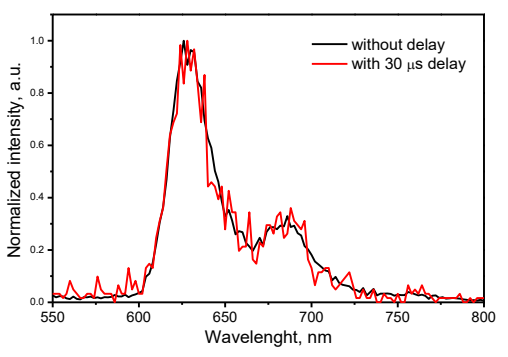

a)

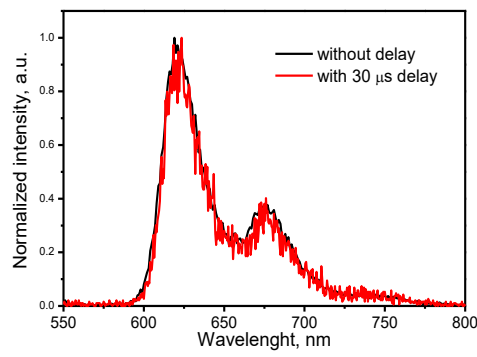

b)

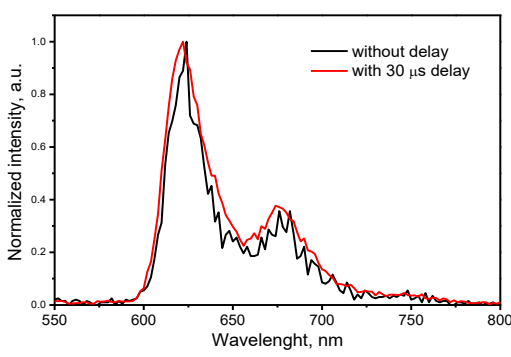

c)

Figure S4. Time-resolved PL spectra without delay and with $30 \mu$ s delay for $5 \mathrm{wt} \%$ solid solutions of compounds 5 (a), 6 (b) and 7 (c) in $\mathrm{mCP}$. The excitation wavelength $\lambda_{\mathrm{ex} .}=350 \mathrm{~nm}$ was used for the PL spectra measurements.

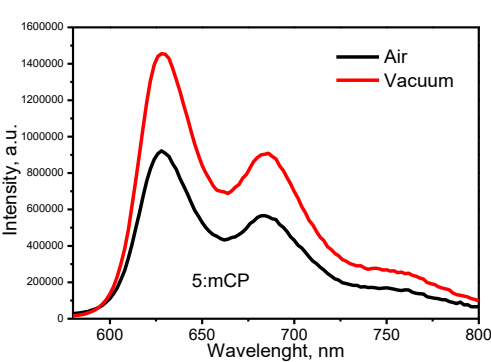

a)

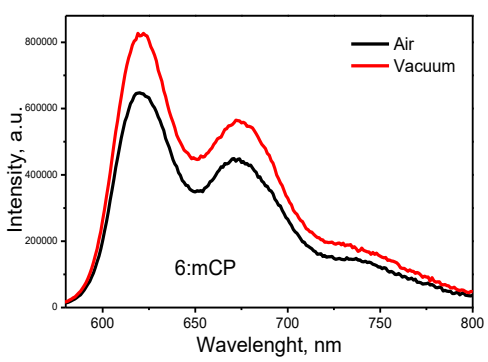

b)

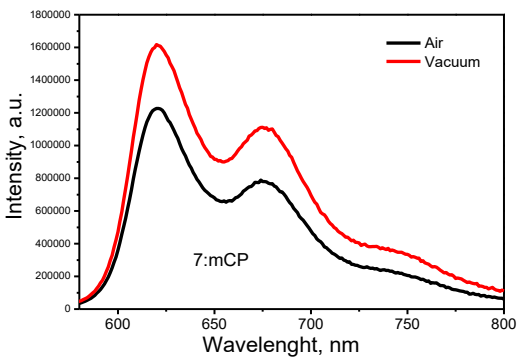

c)

Figure S5. PL spectra of compound 5 (a), 6 (a) and 7 (b) in 5 wt\% doped films using the mCP host at air and vacuum conditions. The excitation wavelength $\lambda_{\text {ex. }}=350 \mathrm{~nm}$ was used for the PL spectra measurements. 

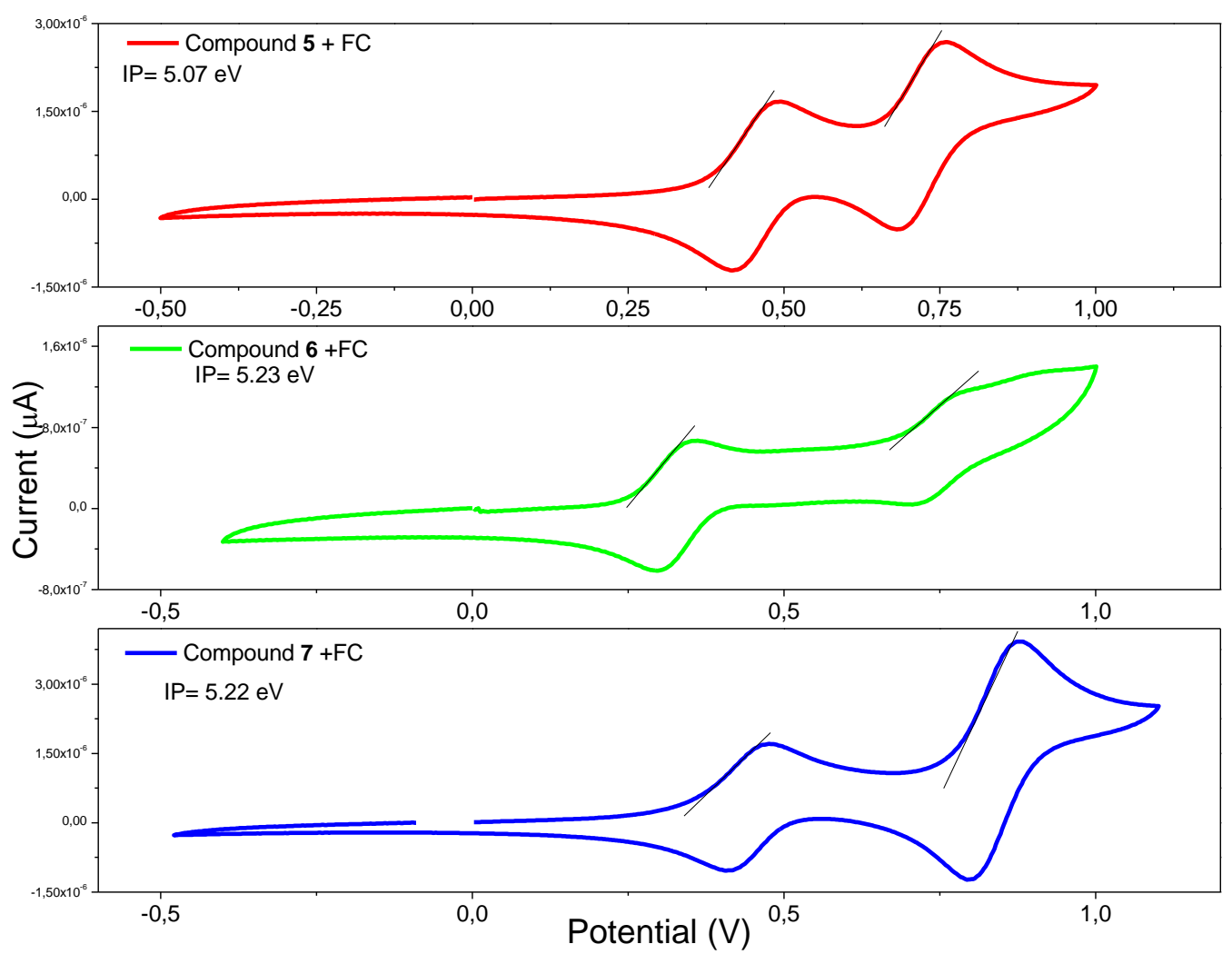

Figure S6. Cyclic voltammograms of dilute solutions of compounds 5-7 in dichloromethane at sweep rate of $0.1 \mathrm{~V} / \mathrm{s}$.
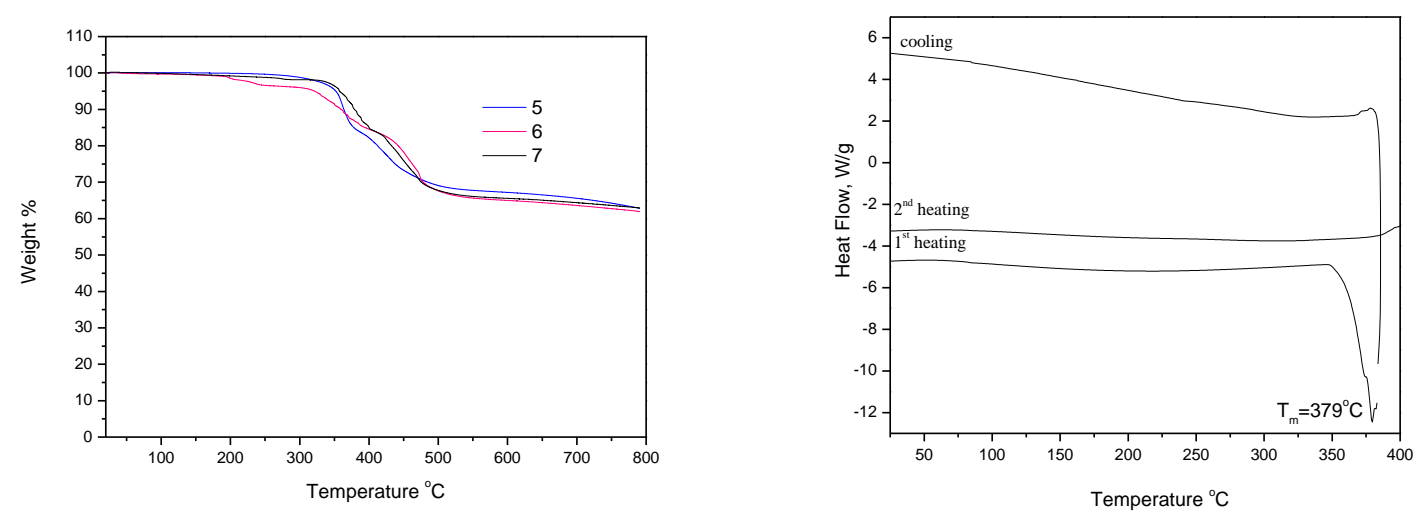

(a) (b)

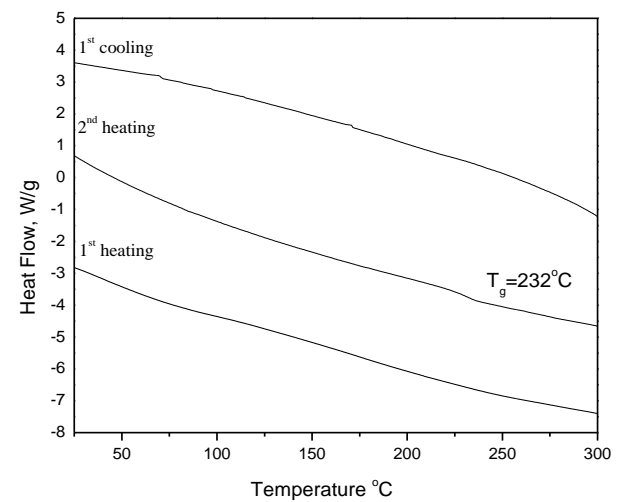

(c)

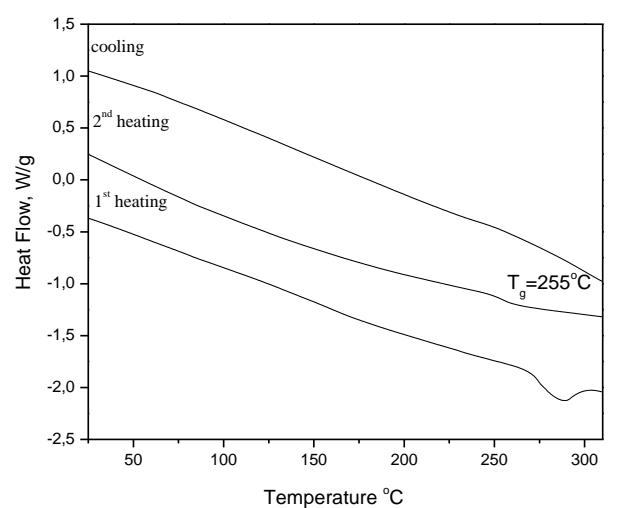

(d)

Figure S7. TGA curves of compounds $\mathbf{5 - 7}$ (a), scan rate of $20^{\circ} \mathrm{C} / \mathrm{min}$. N2 atmosphere and DSC curves of compounds 5 (b), 6 (c), 7 (d), scan rate of $10^{\circ} \mathrm{C} / \mathrm{min}$. $\mathrm{N} 2$ atmosphere. 


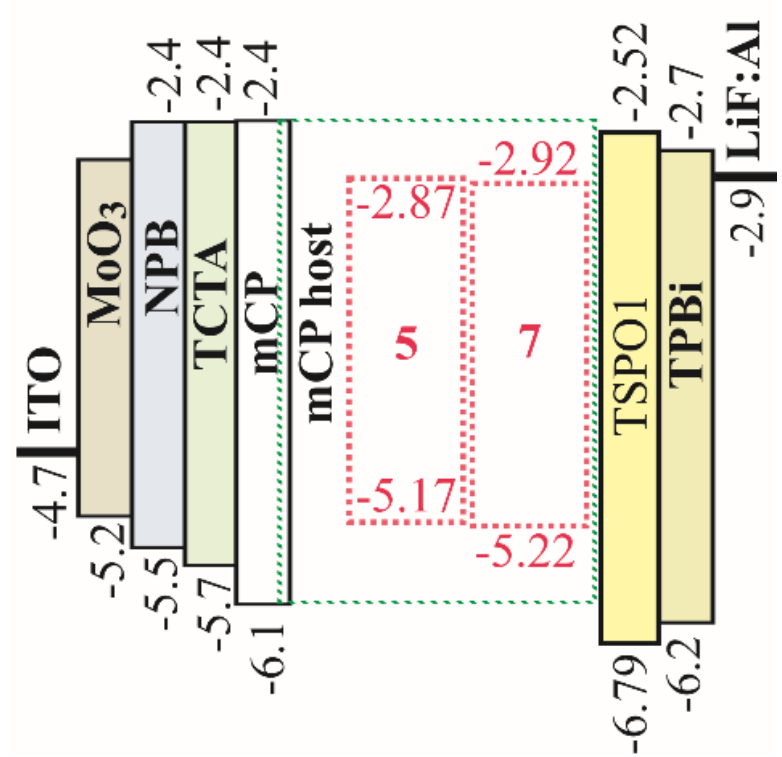

Figure S8. Equilibrium energy diagrams of devices R1 and R2. 


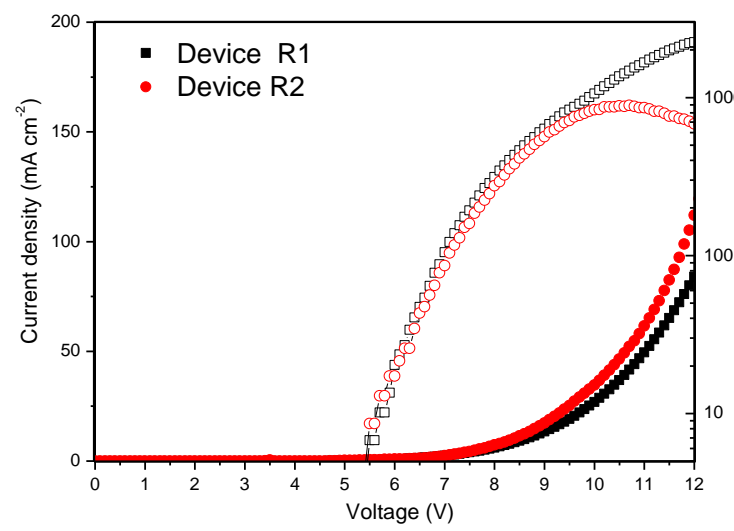

a)

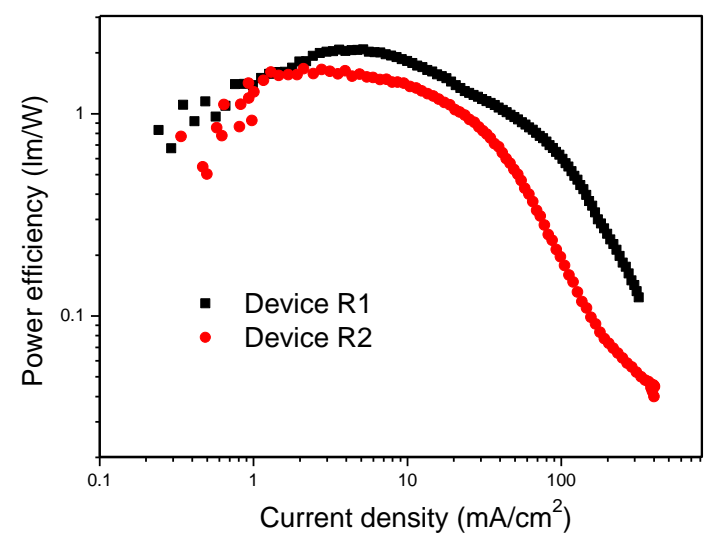

c)

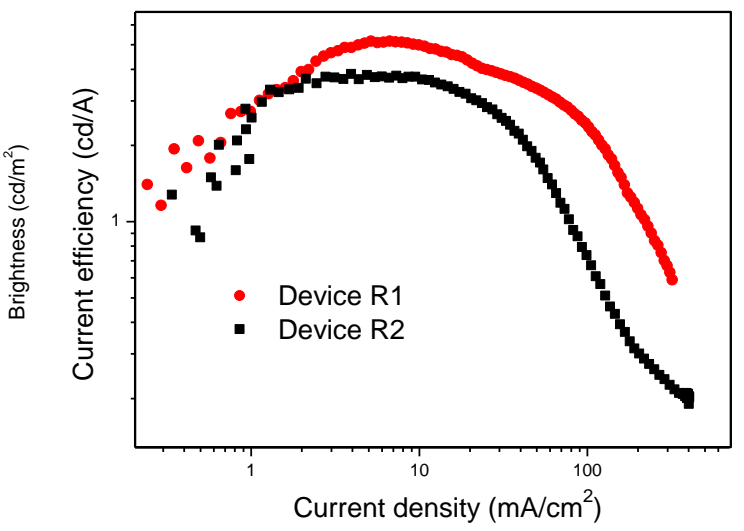

b)

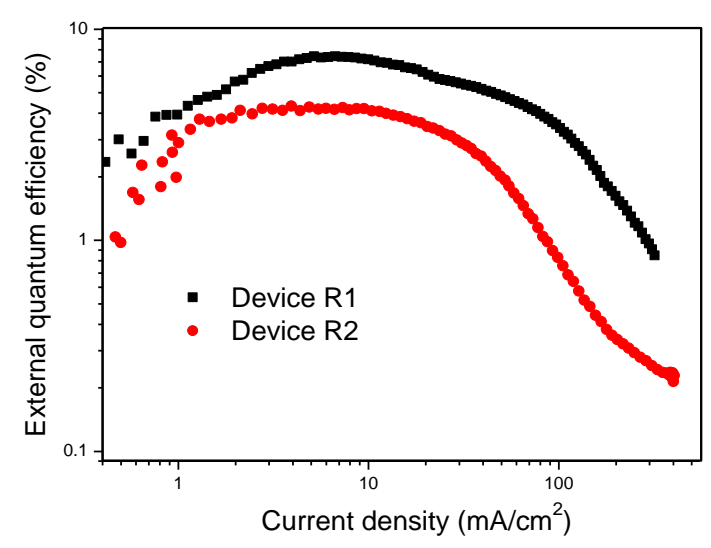

d)

Figure S9. Current density/brightness versus voltage characteristics (a); current (b), power (c), EQE (d) efficiencies of devices R1 and R2. 

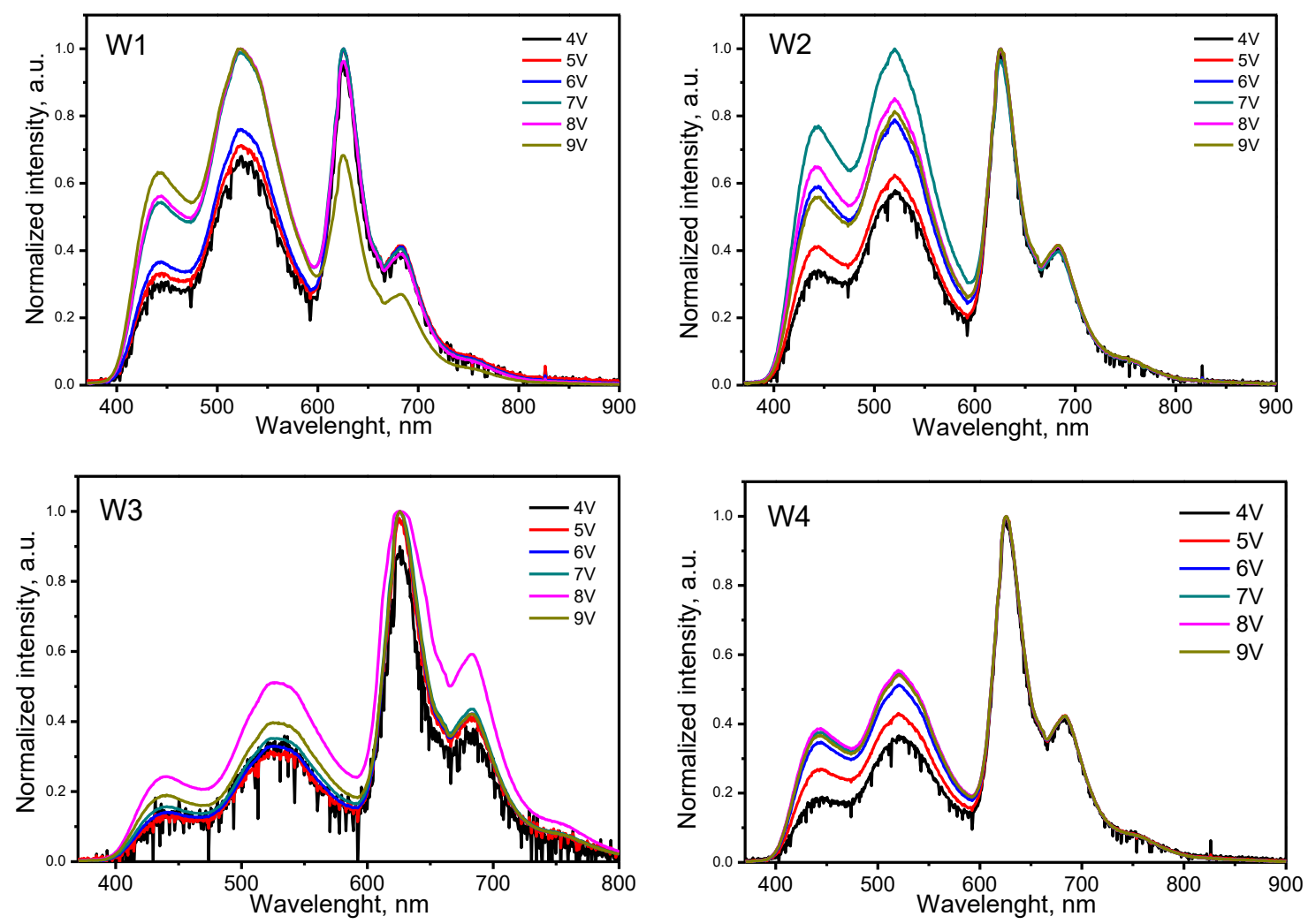

Figure S10. EL spectra of devices W1-W4 at different voltages. 


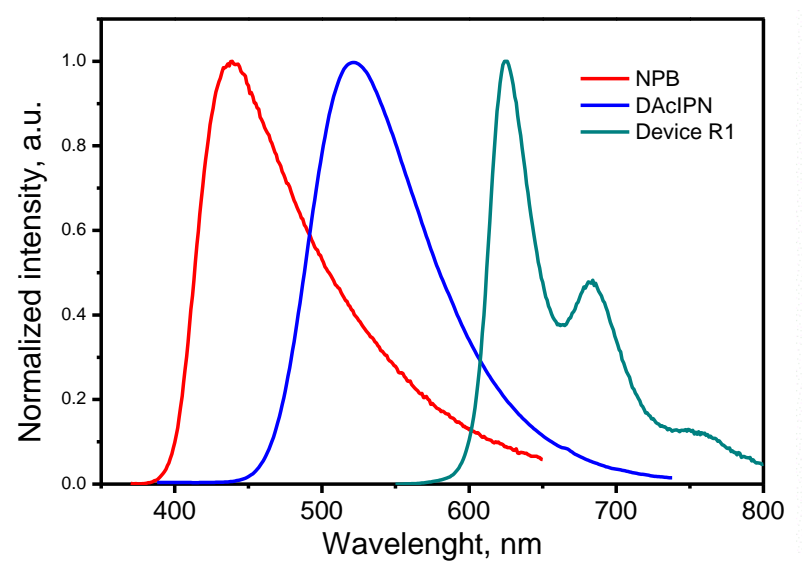

a)

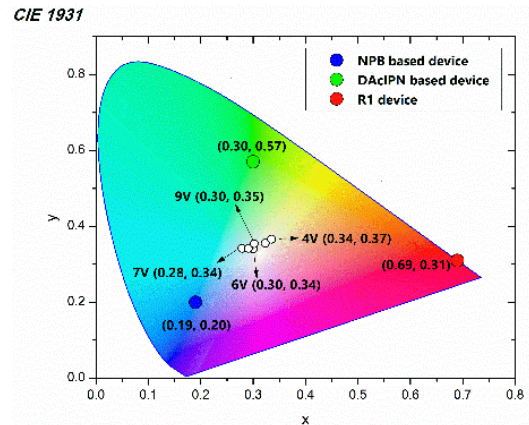

c)

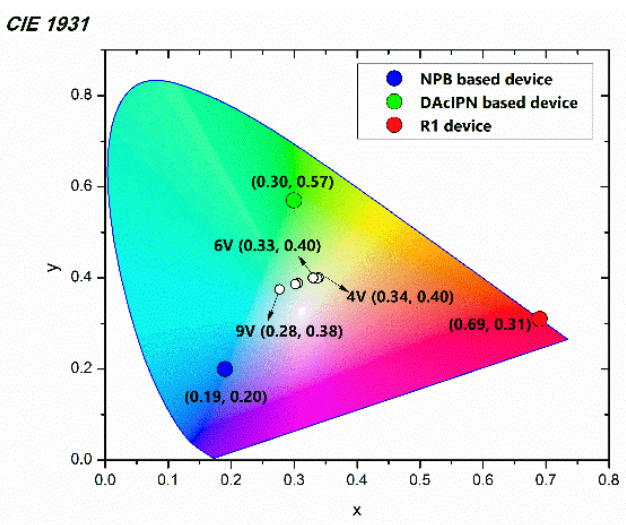

b)

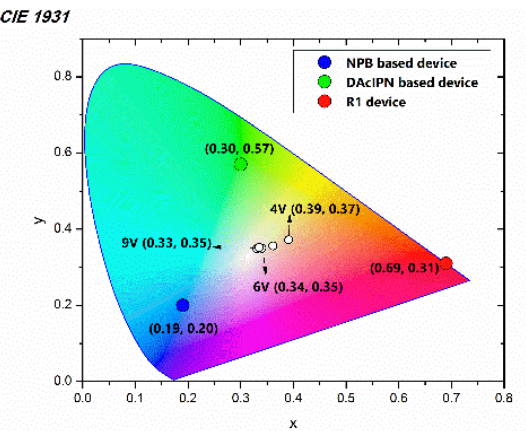

d)

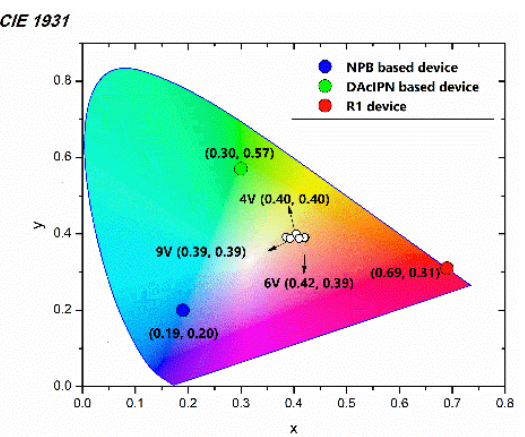

e)

Figure S11. EL spectra (a) for devices based on NPB, DAcIPN, complex 5. CIE1931 coordinates for EL spectra of devices W1 (b), W2(c), W3 (d) W4 (e) at different voltages (see white points). 


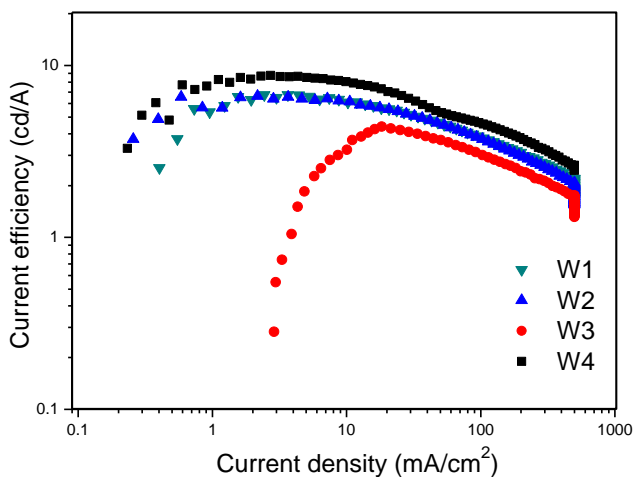

a)

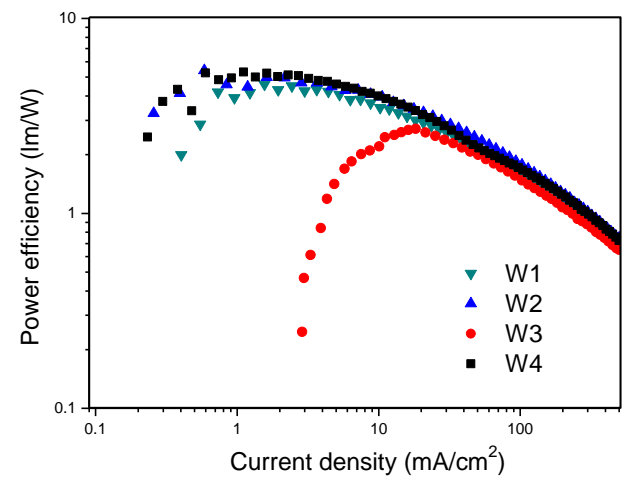

b)

Figure S12. Current (a) and power (b) efficiencies of devices W1-W4. 


\section{NMR spectra}

${ }^{1} \mathrm{H}$ NMR spectra of 2-((2-bromophenyl)ethynyl)pyridine (2)

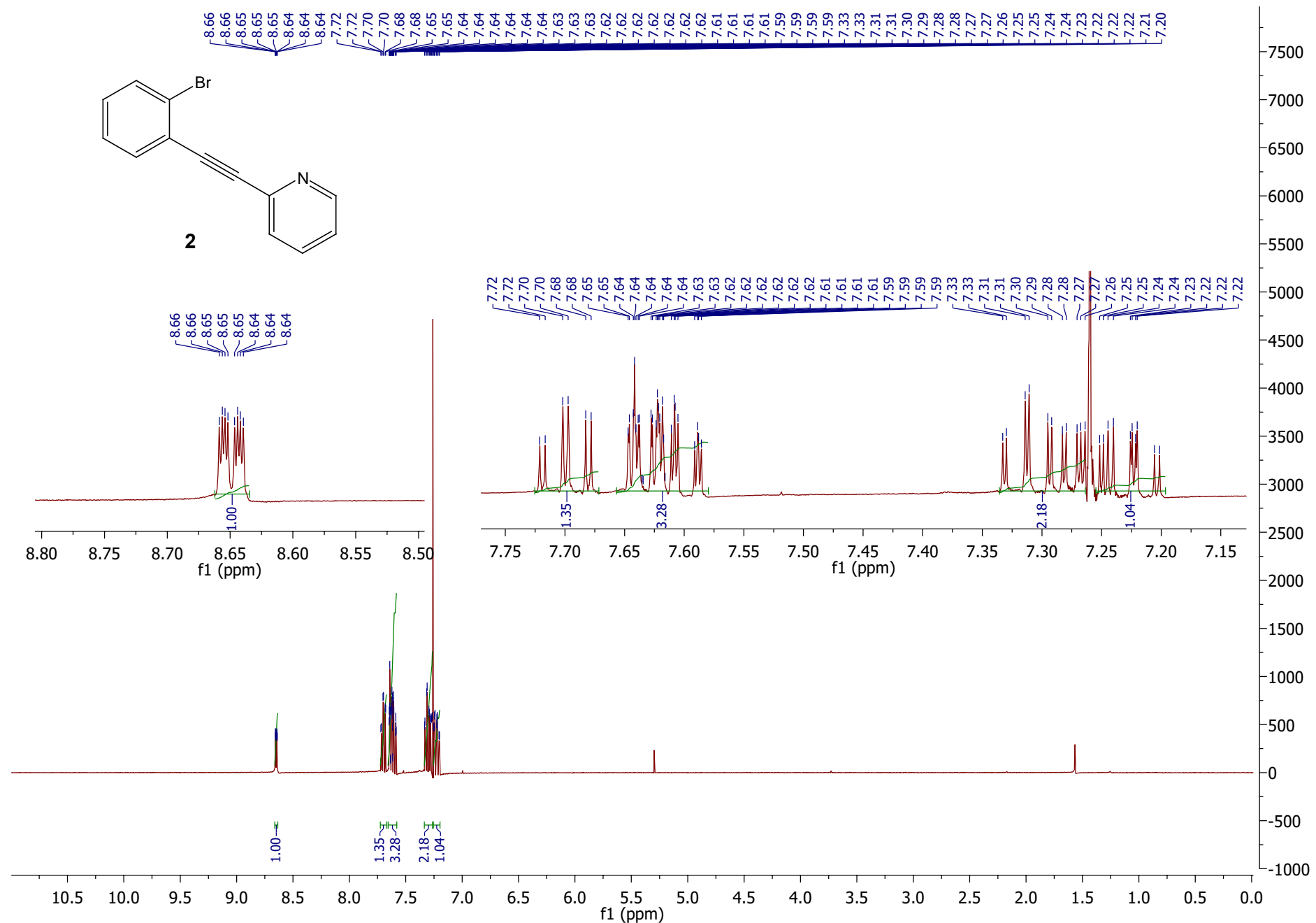


${ }^{1} \mathrm{H}$ NMR spectra of 2-(benzo[b]selenophen-2-yl)pyridine (3)

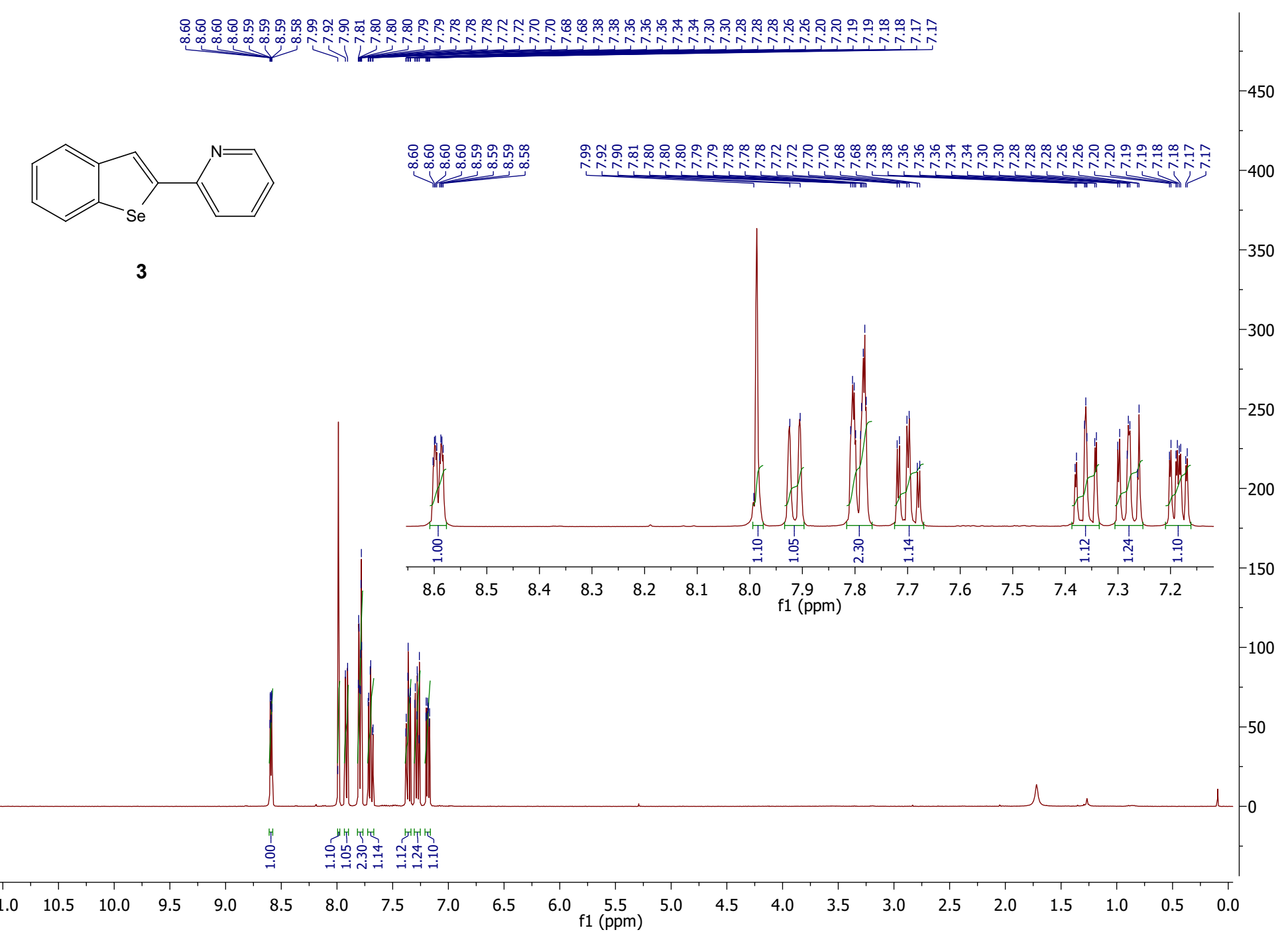


${ }^{13} \mathrm{C}$ NMR spectra of 2 -(benzo[b]selenophen-2-yl)pyridine (3)

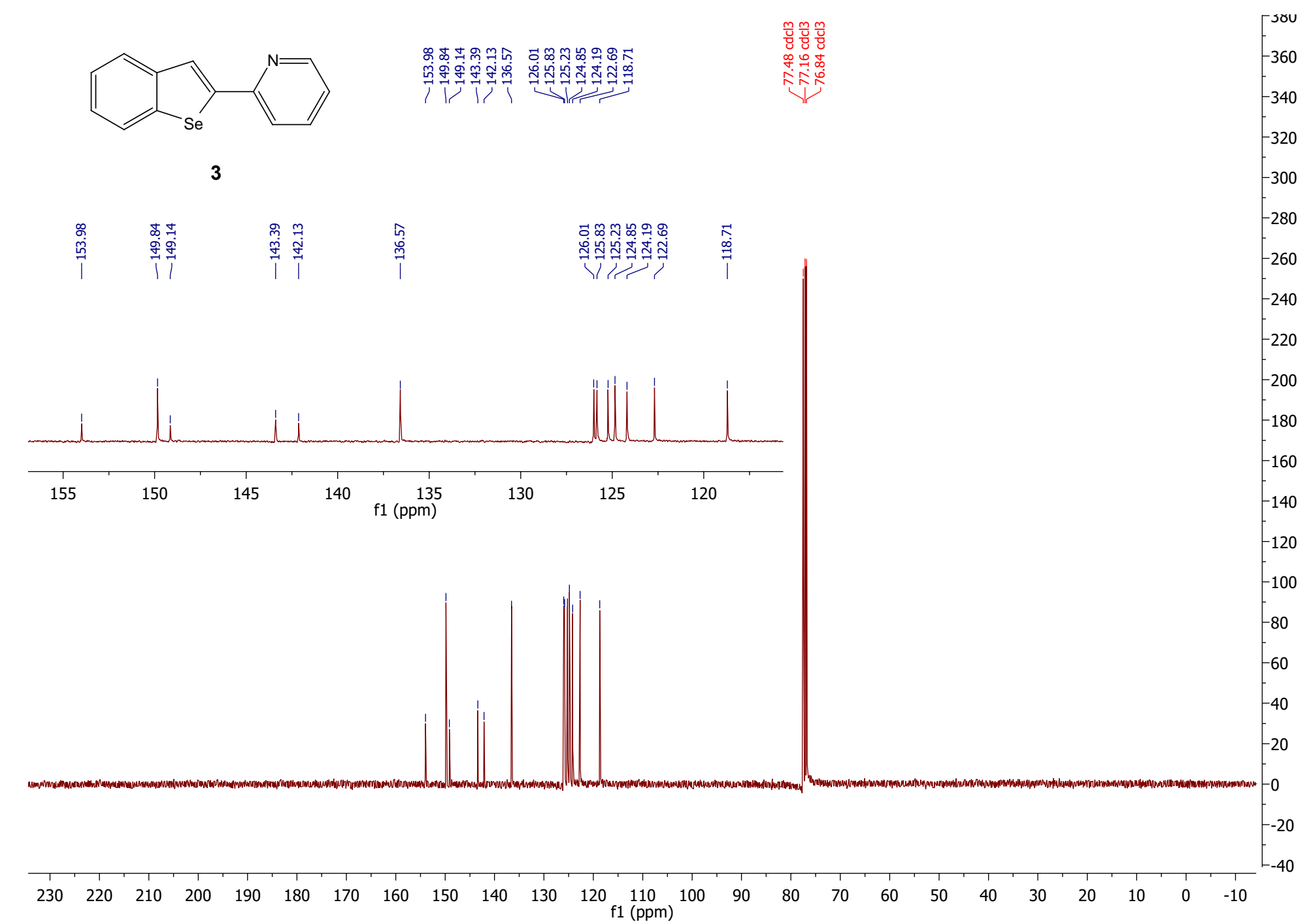


${ }^{77}$ Se NMR spectrum of 2-(benzo[b]selenophen-2-yl)pyridine (3)

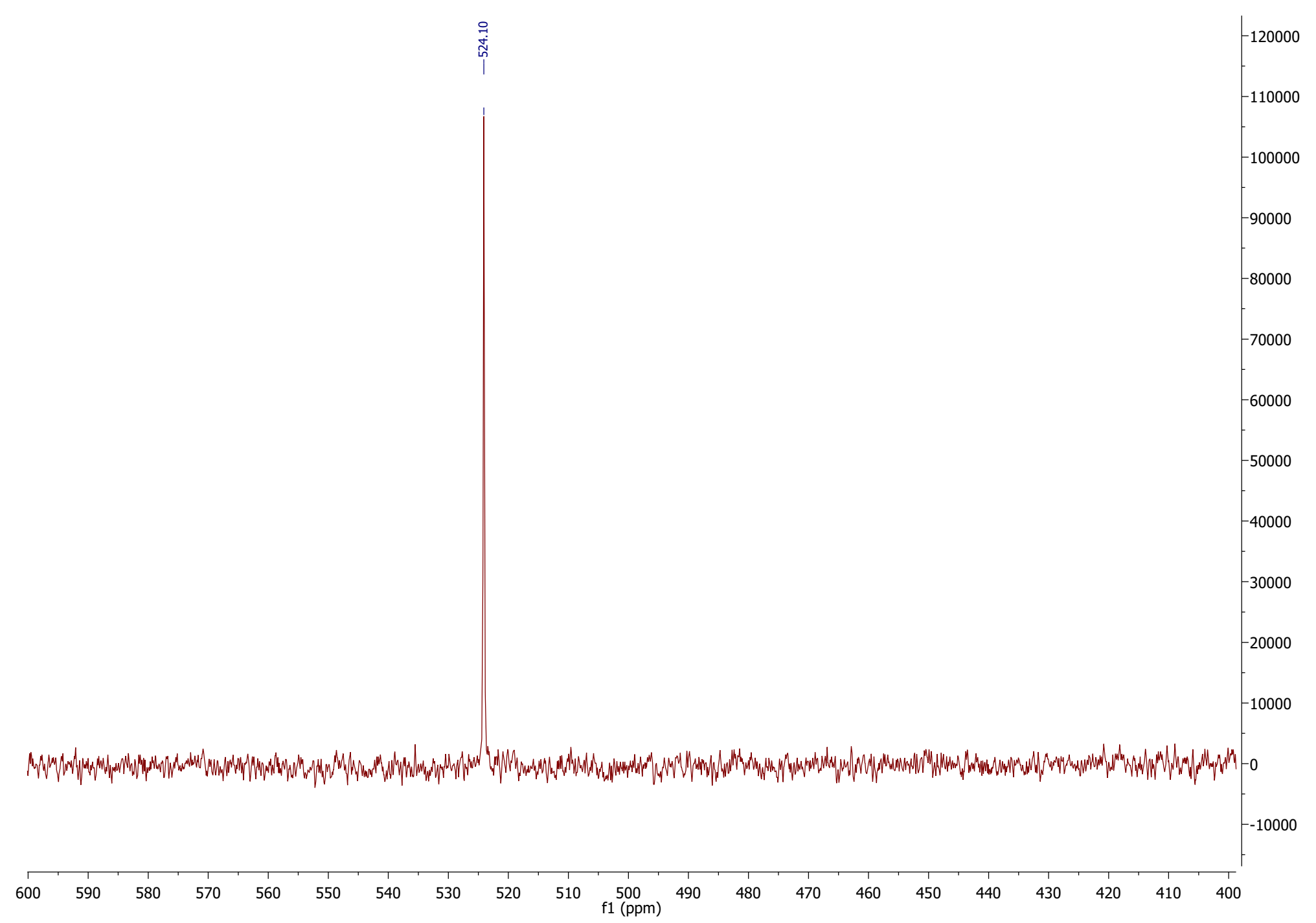


${ }^{1} \mathrm{H}$ NMR spectra of [(BSe) $\left.2 \operatorname{lr}(\mathrm{acac})\right]$ (5)

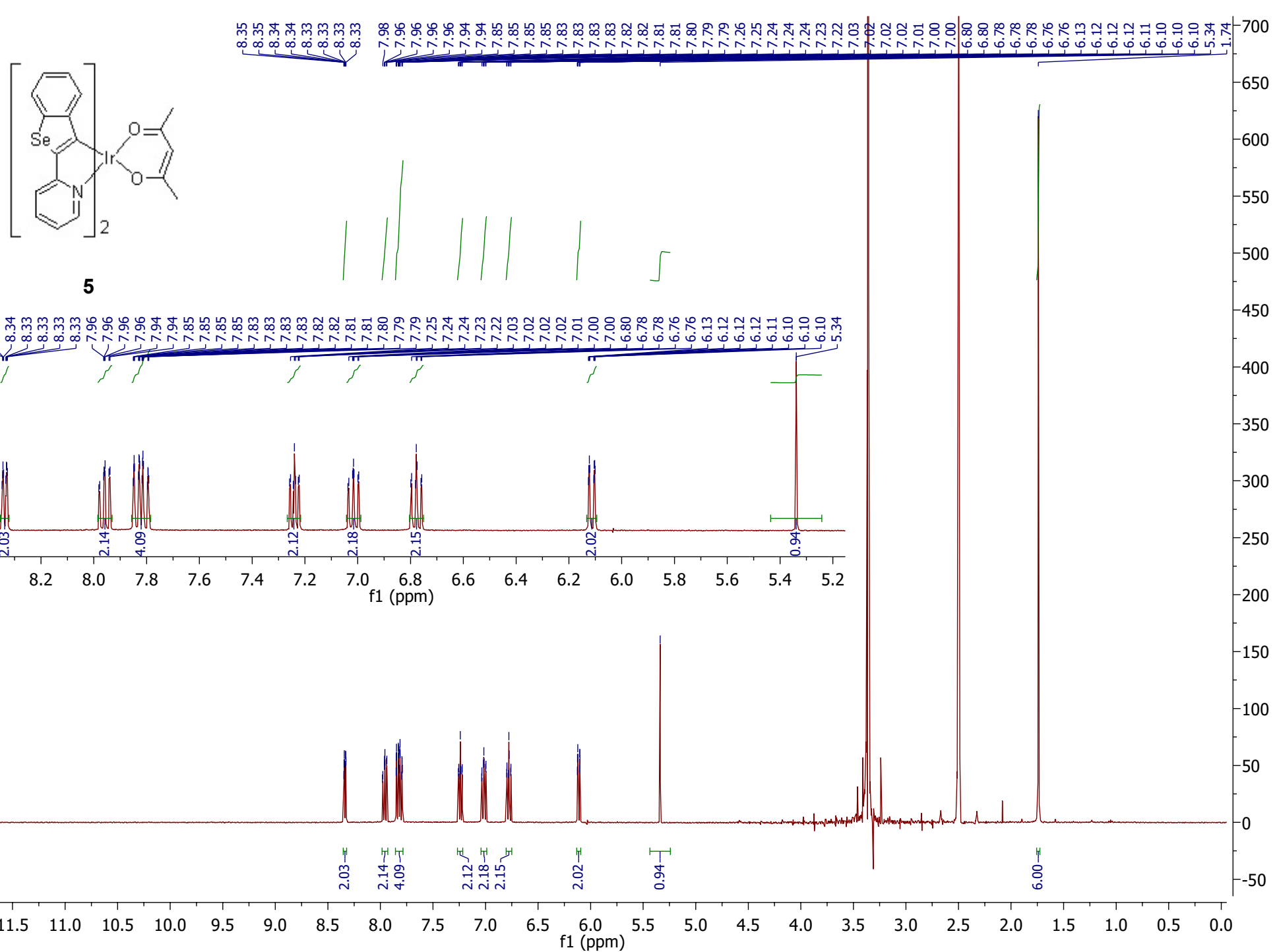


${ }^{77} \mathrm{Se} N M R$ spectrum of [(BSe $\left.)_{2} \operatorname{lr}(\mathrm{acac})\right]$ (5)

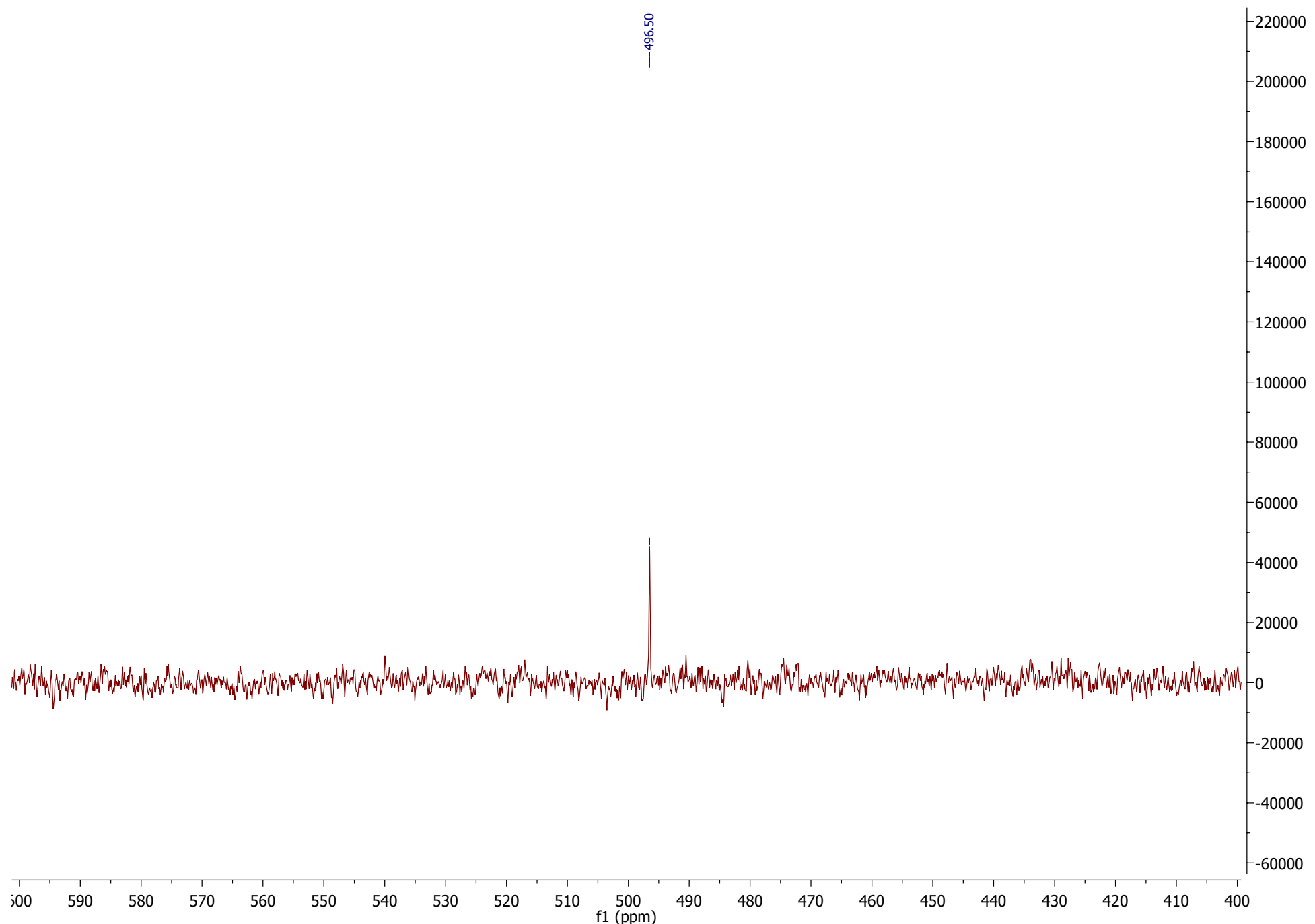


HR mass spectrum of [(BSe) $\left.)_{2} \operatorname{rr}(\mathrm{acac})\right]$ (5)

HRMS_2018_02_068 885 (2.485) Cm (882:914-(838:854+964:980))
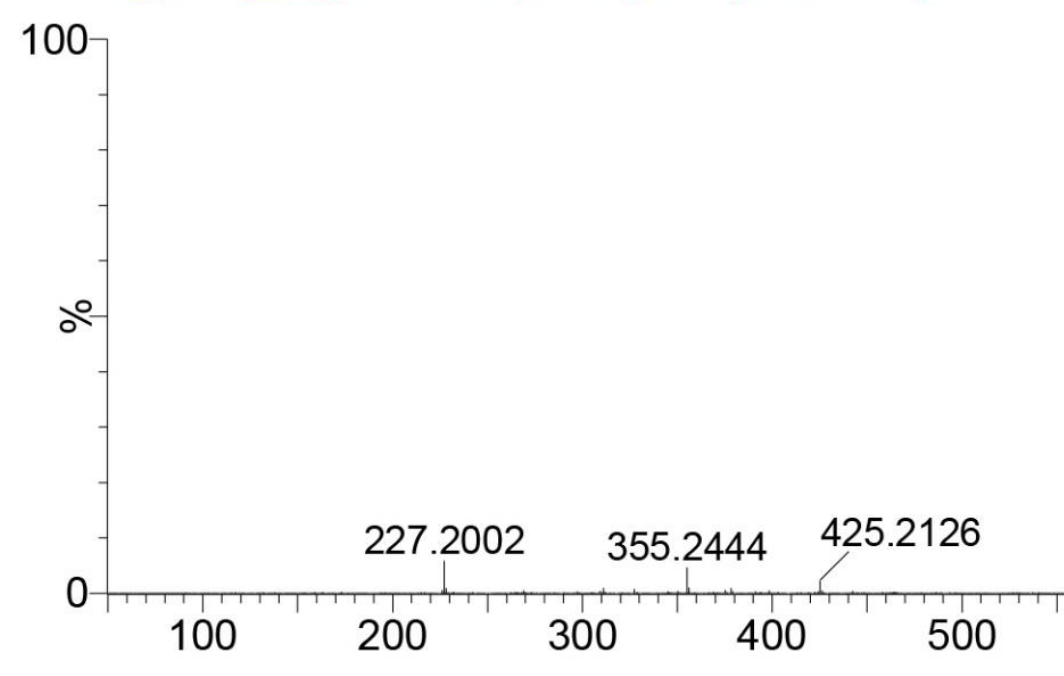

1: TOF MS ES+

1.32e6

807.9727

808.9763

809.9750

810.9769

900 
IR spectrum of [(BSe) $\left.{ }_{2} \operatorname{Ir}(\mathrm{acac})\right]$ (5)

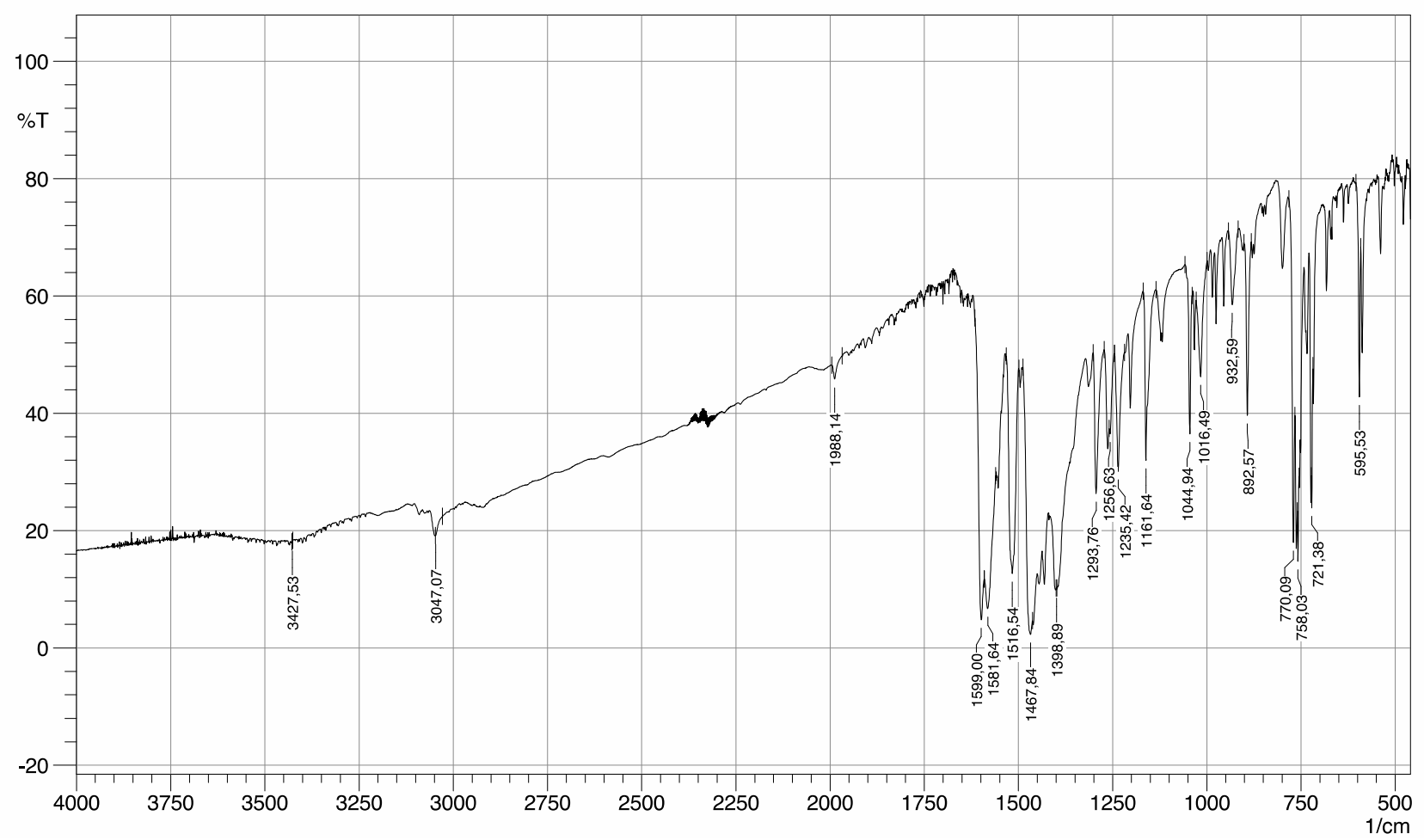

A-316 
${ }^{1} \mathrm{H}$ NMR spectra of [(BSe $\left.)_{2} \operatorname{lr}(\mathrm{Pic})\right](6)$

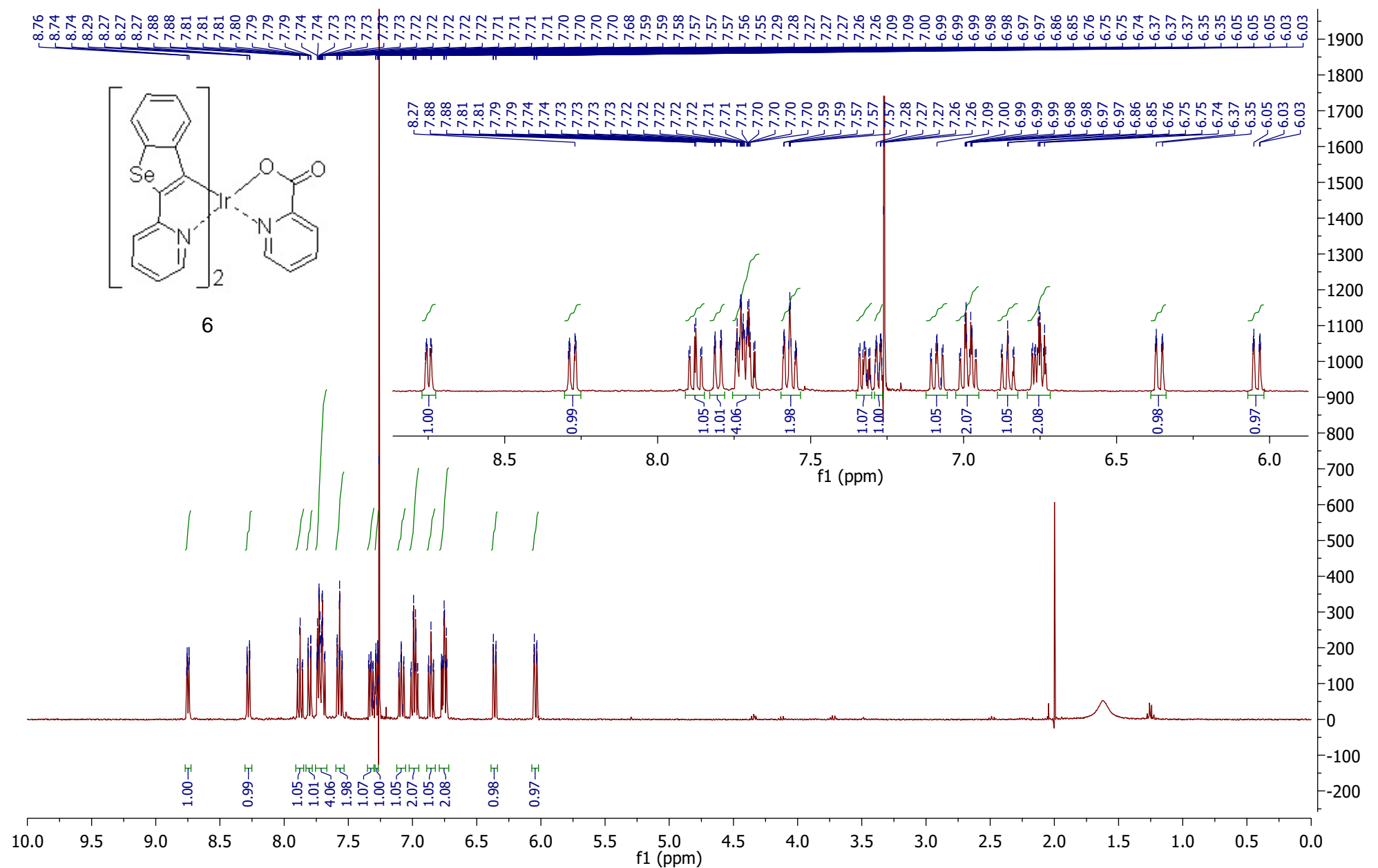


${ }^{13} \mathrm{C}$ NMR spectra of $\left.[(\mathrm{BSe}))_{2} \mathrm{Ir}(\mathrm{Pic})\right](6)$

我

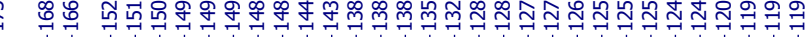

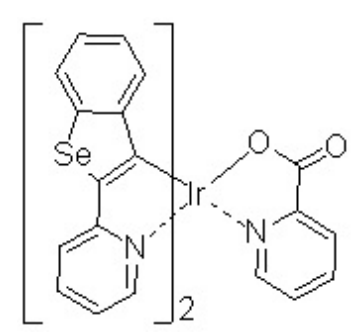

6

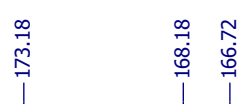

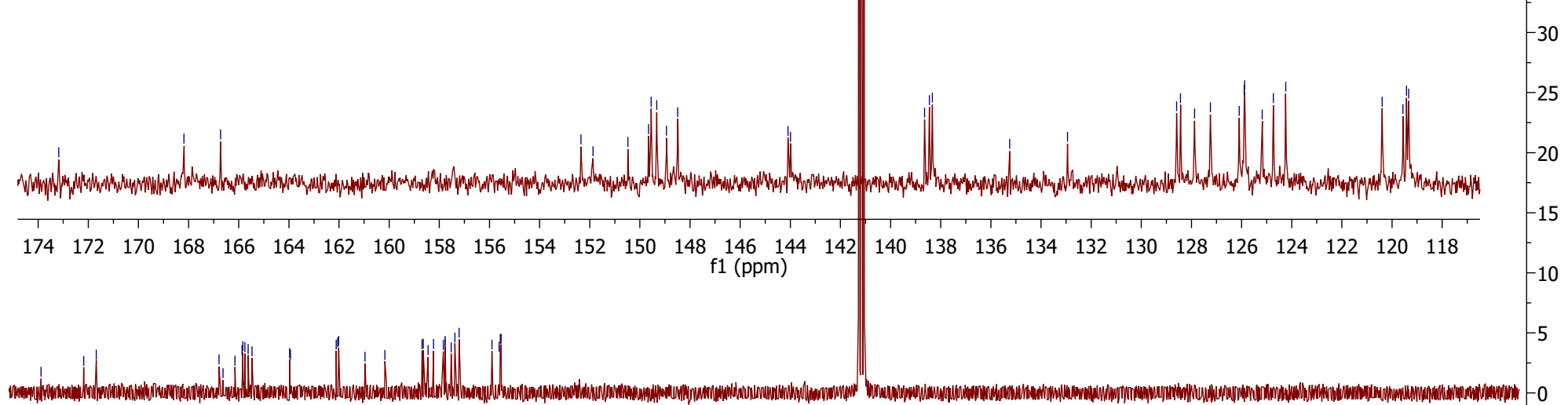

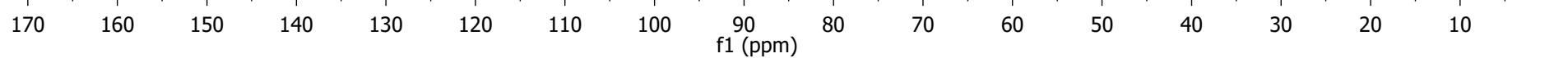


${ }^{77} \mathrm{Se} N M R$ spectrum of $\left[(\mathrm{BSe})_{2} \operatorname{lr}(\mathrm{Pic})\right](6)$

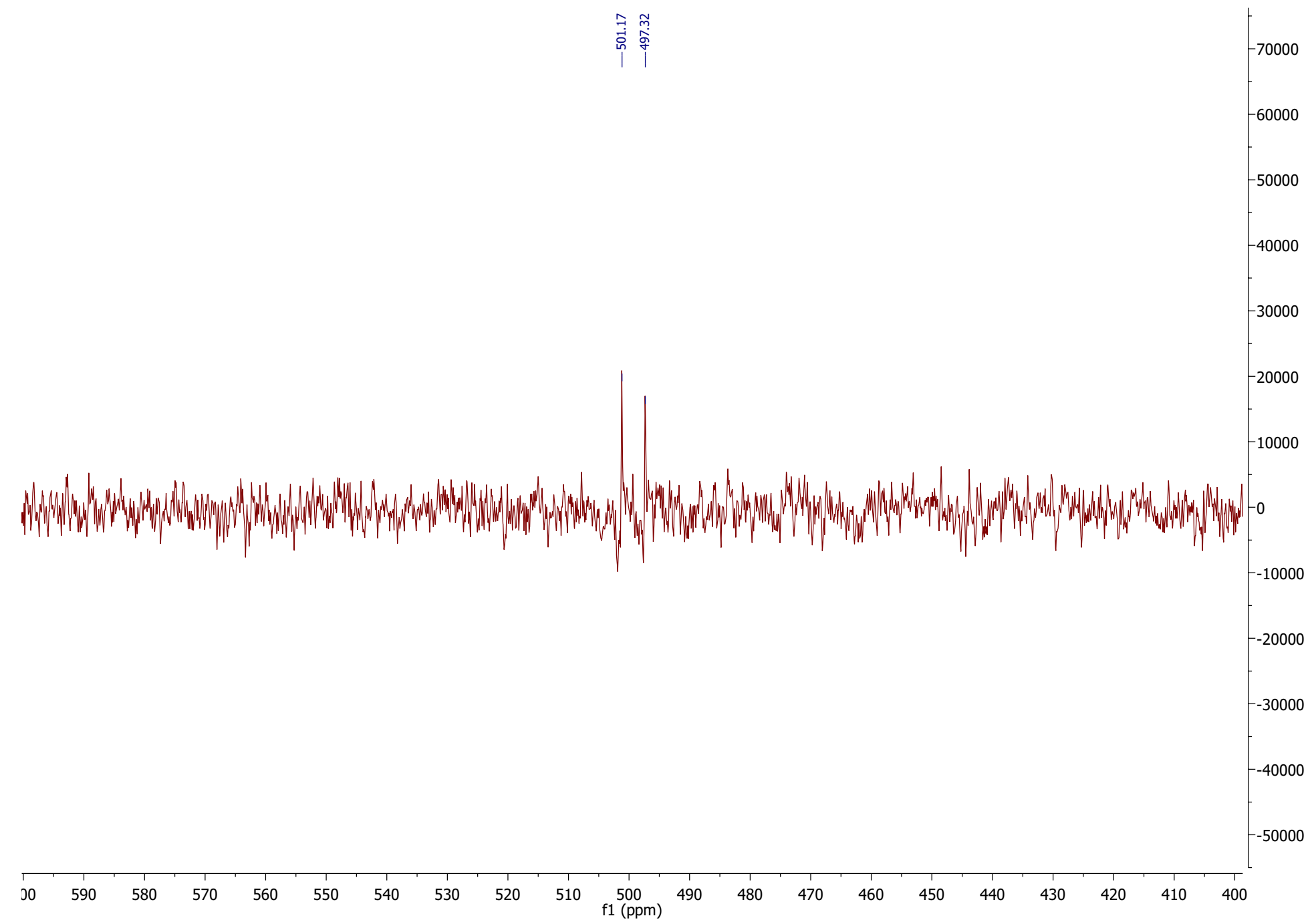


HR mass spectrum of $\left[(\mathrm{BSe})_{2} \mathrm{Ir}(\mathrm{Pic})\right](6)$

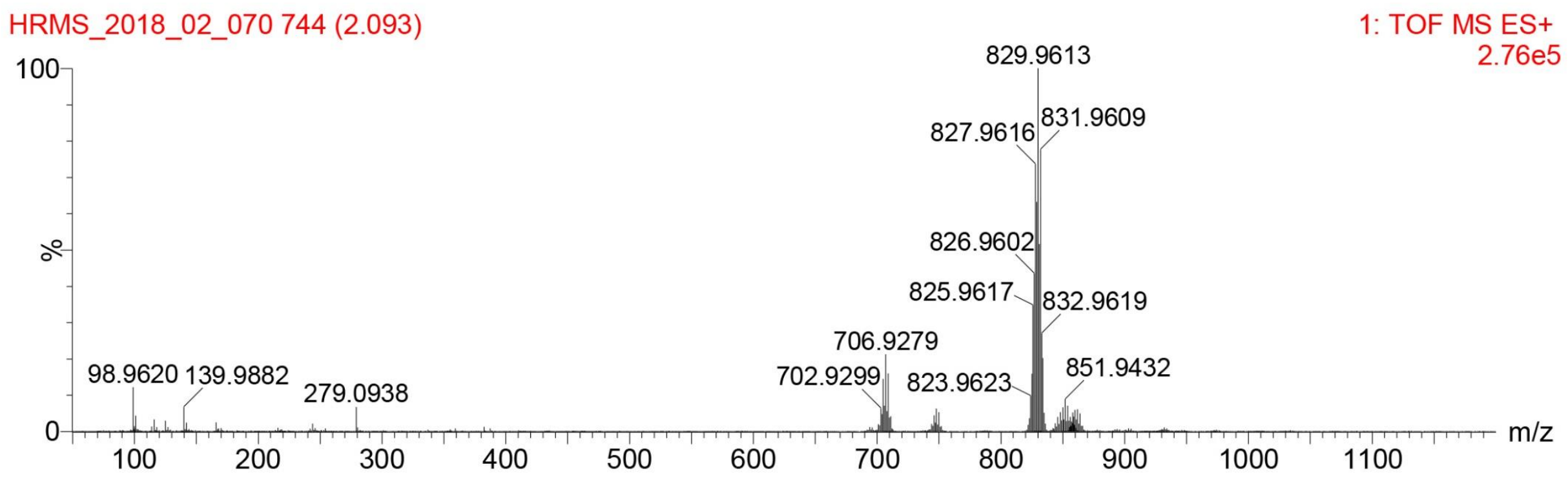


IR spectrum of [(BSe) $\left.)_{2} \operatorname{Ir}(\mathrm{Pic})\right](6)$

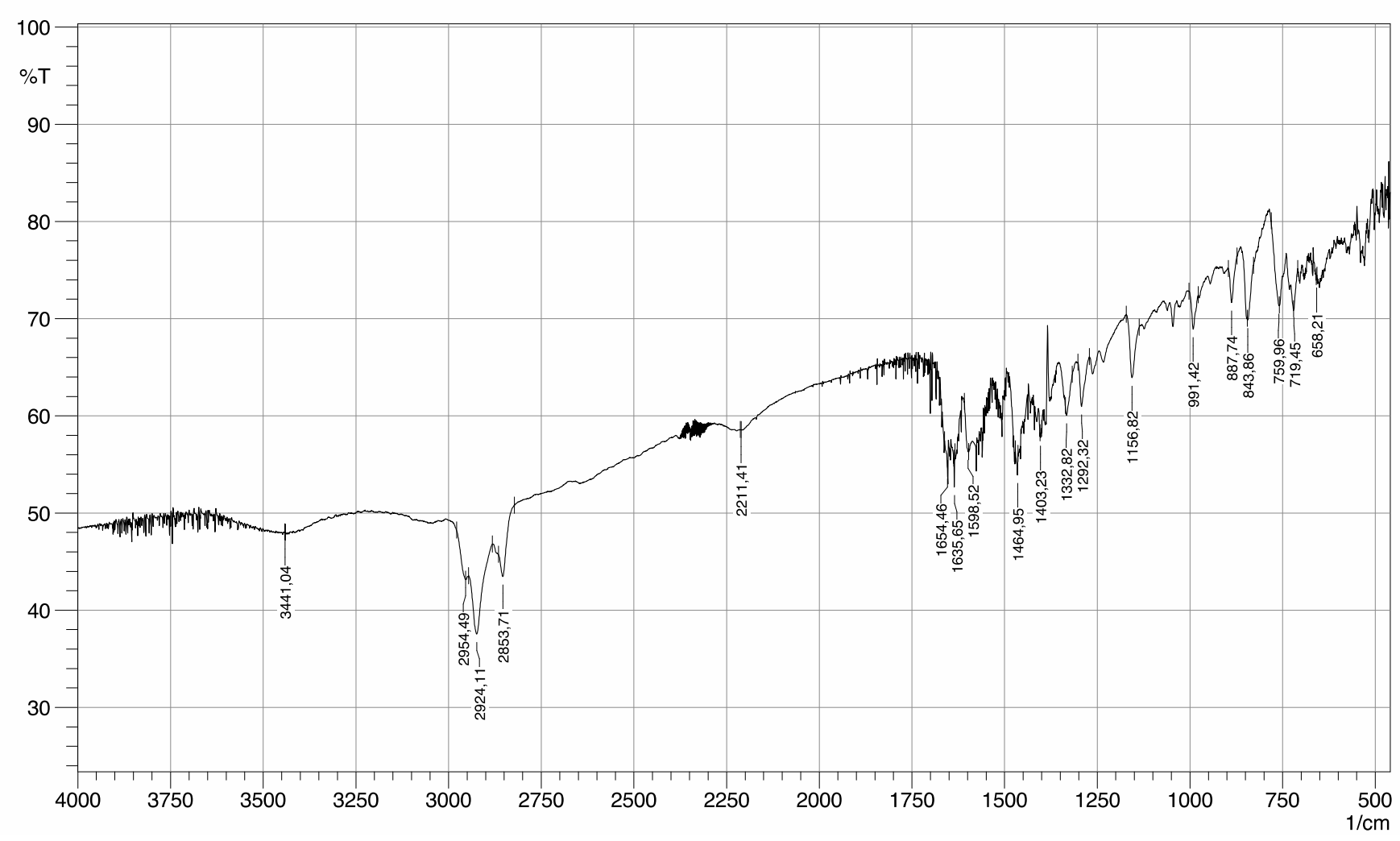


${ }^{1} \mathrm{H}$ NMR spectra of [(BSe) $\left.{ }_{2} \operatorname{lr}(\mathrm{Qui})\right]$ (7)

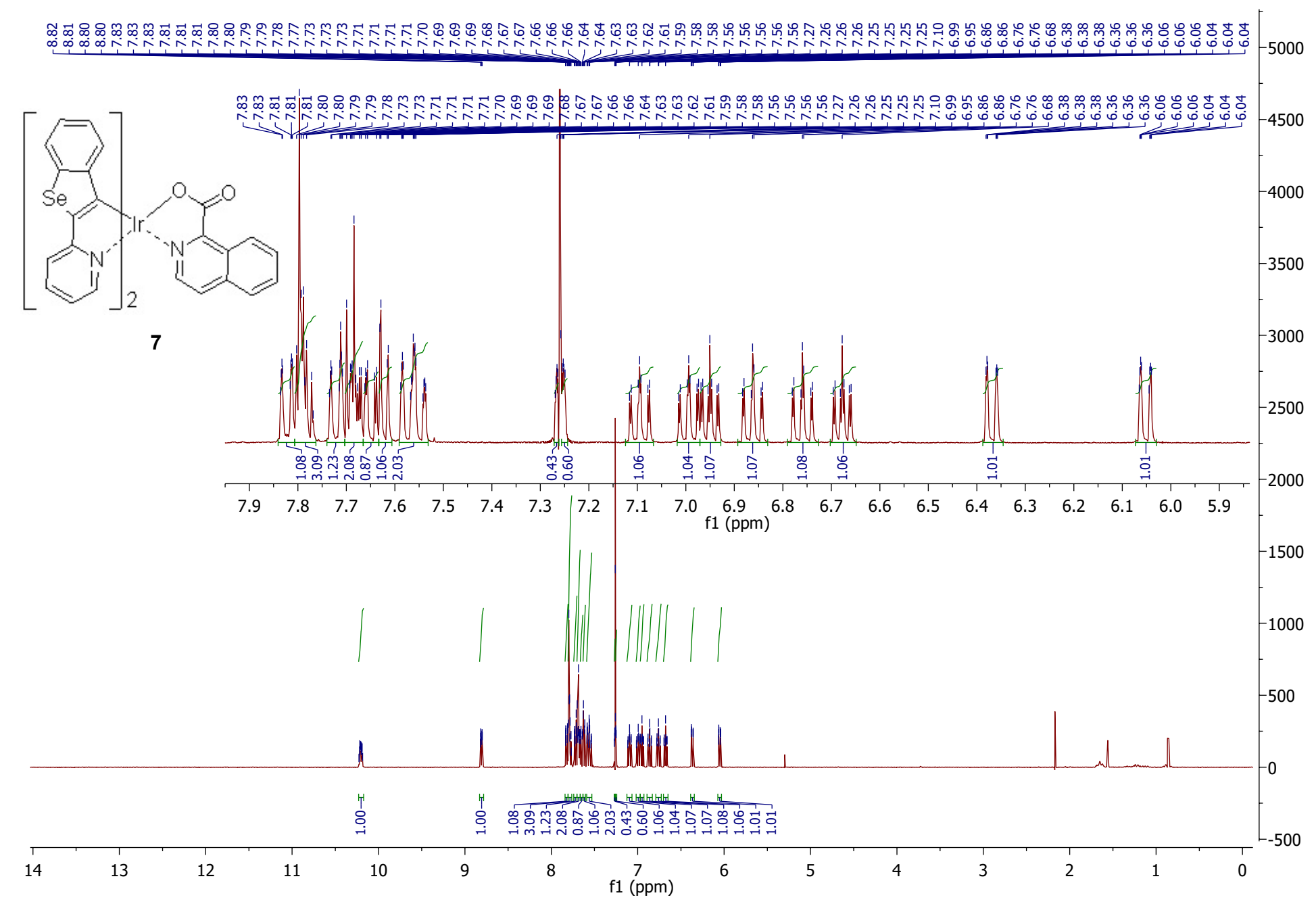


${ }^{13} \mathrm{C}$ NMR spectra of [(BSe) $\left.{ }_{2} \operatorname{lr}(\mathrm{Qui})\right]$ (7)
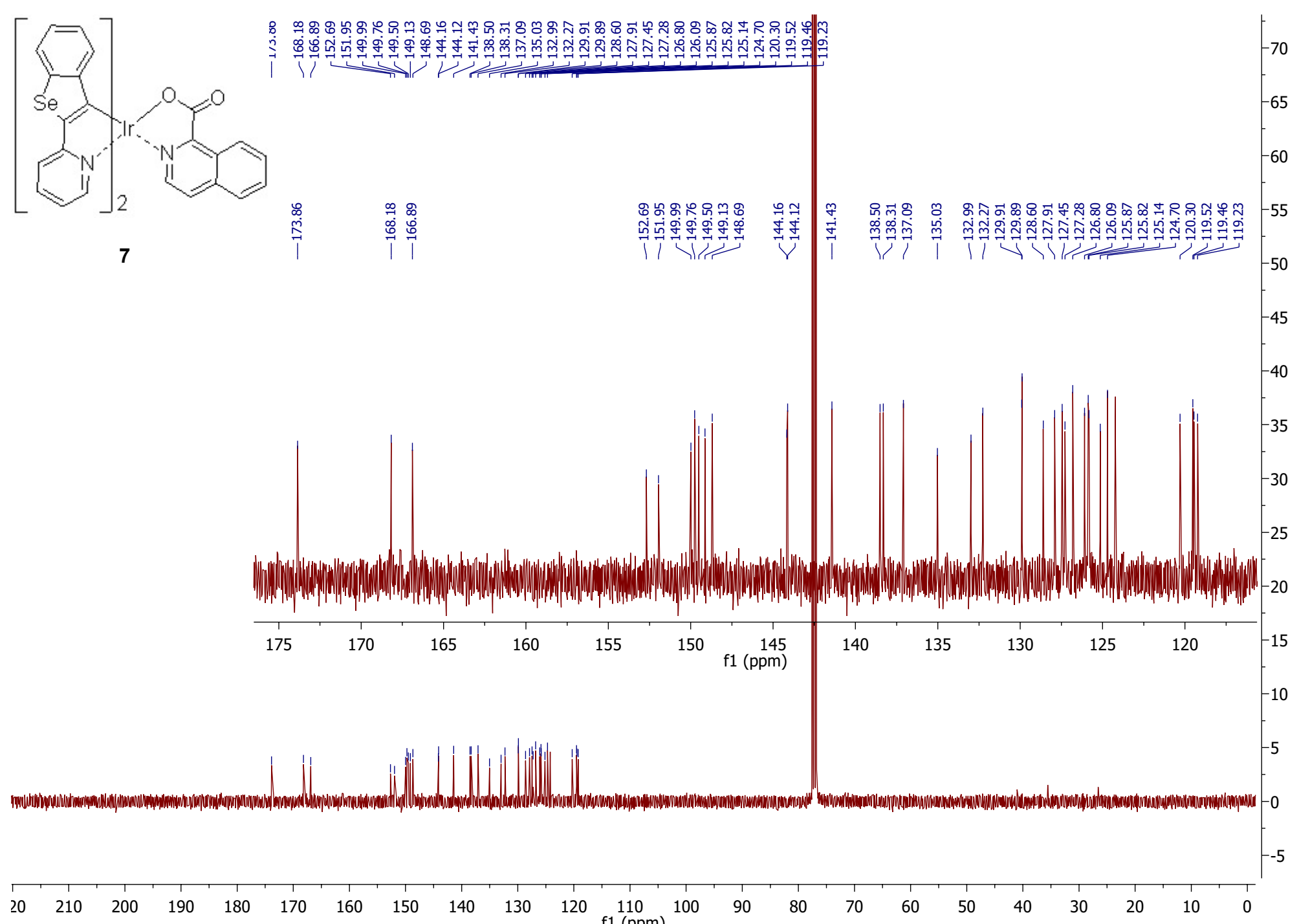
${ }^{77}$ Se NMR spectrum of [(BSe) $\left.{ }_{2} \operatorname{lr}(\mathrm{Qui})\right]$ (7)

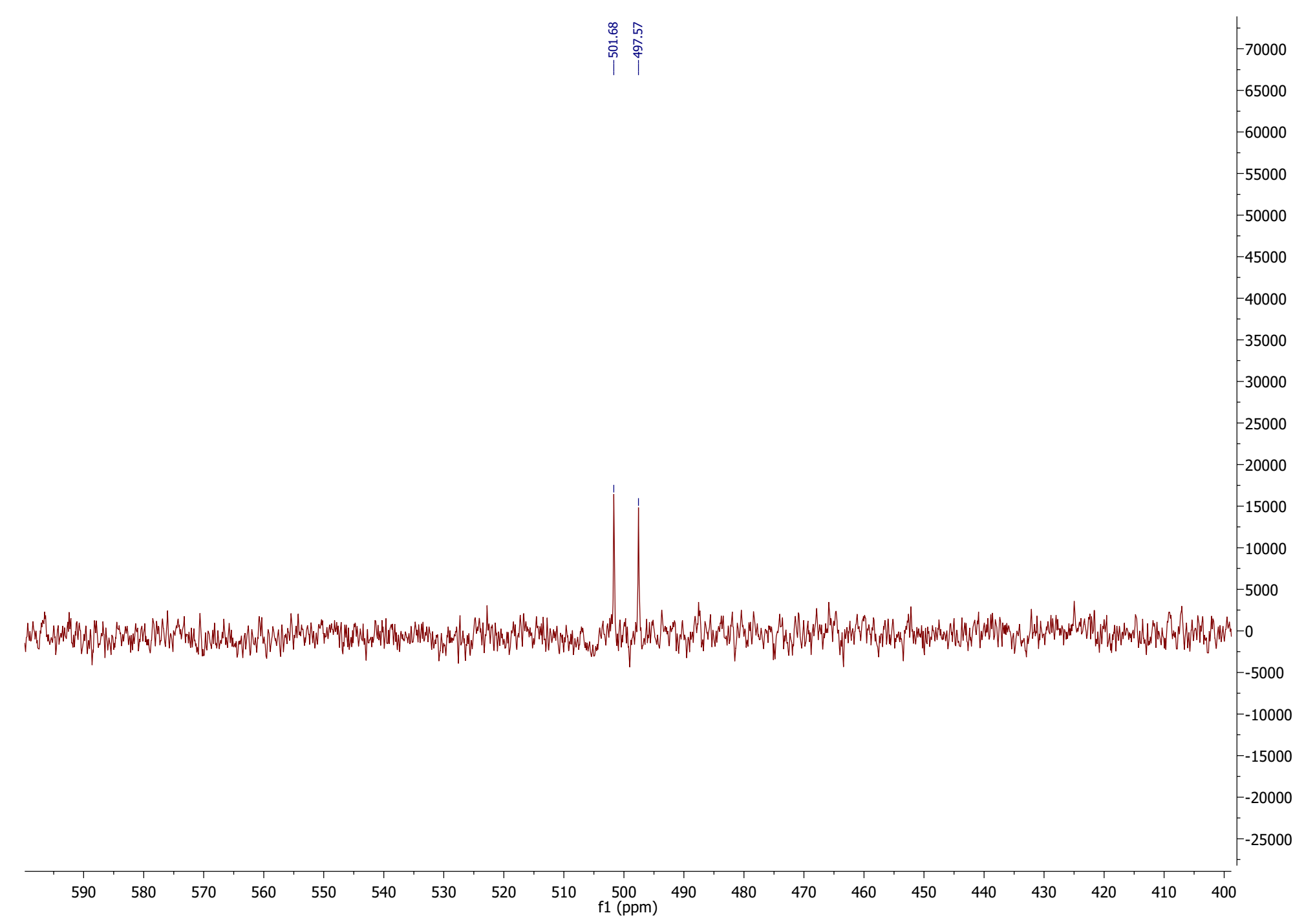


HR mass spectrum of $\left[(\mathrm{BSe})_{2} \operatorname{Ir}(\mathrm{Qui})\right]$ (7)

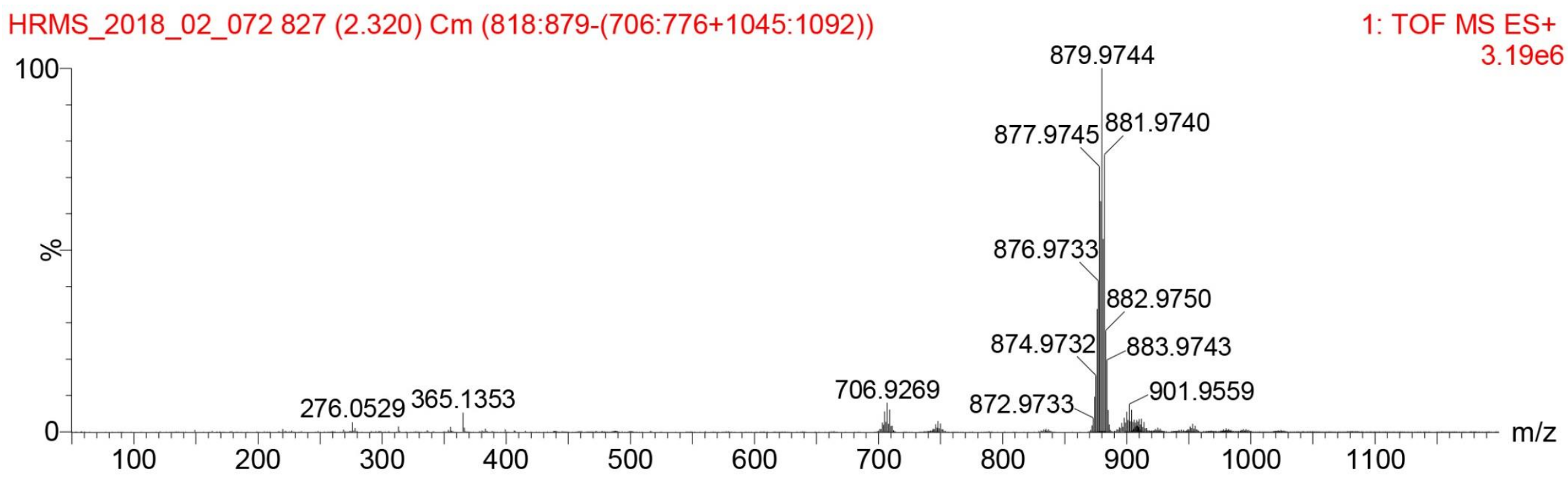




\section{IR spectrum of [(BSe) $\left.{ }_{2} \operatorname{Ir}(\mathrm{Qui})\right]$ (7)}

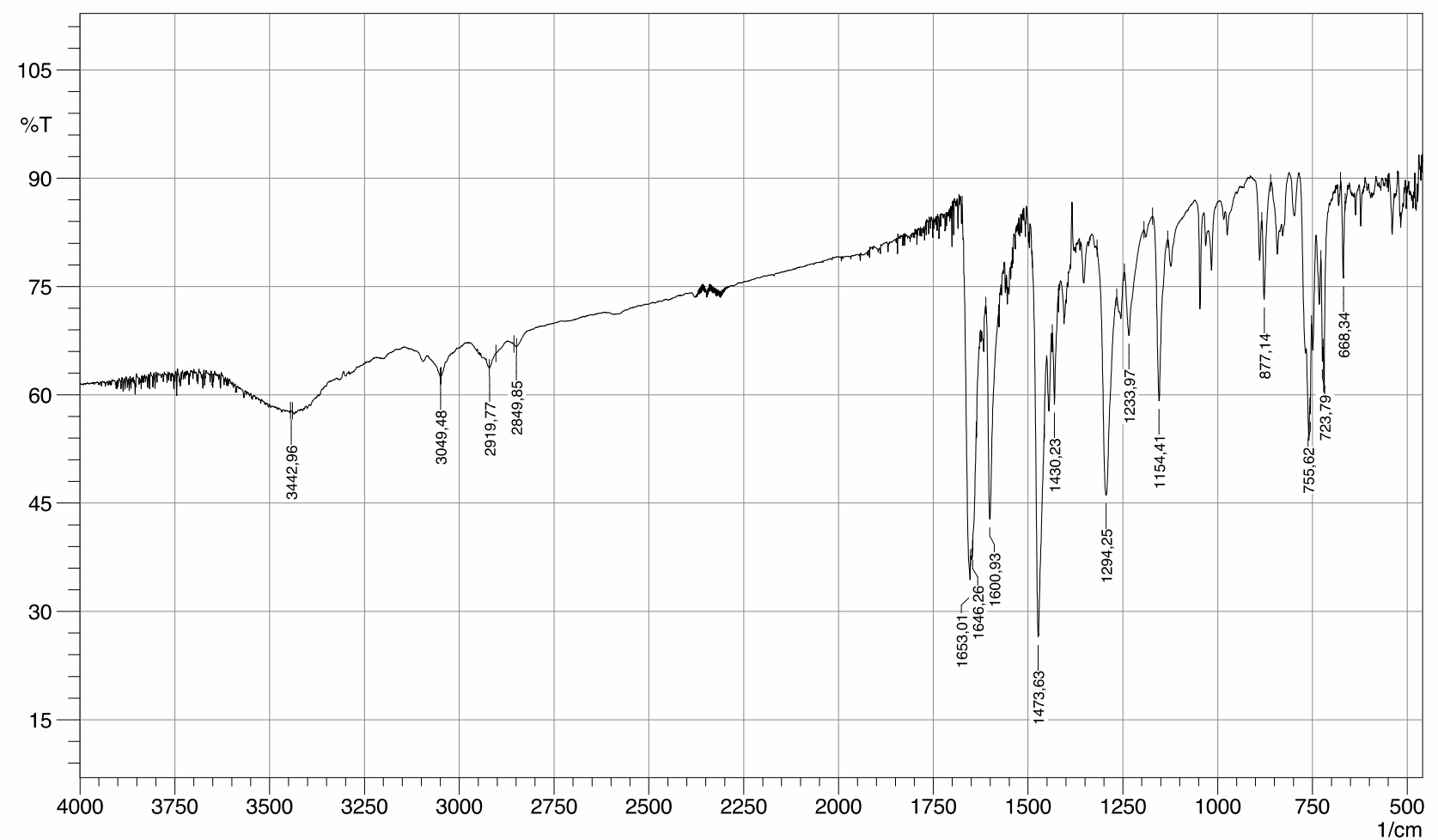

A- 328 


\section{References.}

1 Gudeika D, Grazulevicius JV, Volyniuk D, Juska G, Jankauskas V, Sini G. Effect of ethynyl linkages on the properties of the derivatives of triphenylamine and 1,8-naphthalimide. J Phys Chem C 2015, 119, 28335.

2 Kukhta, N.A.; Volyniuk, D.; Peciulyte, L.; Ostrauskaite, J.; Juska, G.; Grazulevicius, J. V., Structure-Property Relationships of Star-Shaped Blue-Emitting Charge-Transporting 1,3,5-Triphenylbenzene Derivatives. Dyes Pigm. 2015, 117, 122. 